\title{
Pyroshock Prediction of Ridge-Cut Explosive Bolts Using Hydrocodes
}

\author{
Juho Lee, ${ }^{1}$ Dae-Hyun Hwang, ${ }^{1}$ Jae-Kyeong Jang, ${ }^{2}$ Dong-Jin Kim, ${ }^{3}$ \\ YeungJo Lee, ${ }^{4}$ Jung-Ryul Lee, ${ }^{1}$ and Jae-Hung Han ${ }^{1}$ \\ ${ }^{1}$ Department of Aerospace Engineering, KAIST, 291 Daehak-ro, Yuseong-gu, Daejeon 34141, Republic of Korea \\ ${ }^{2}$ Department of Aerospace Engineering, Chonbuk National University, 567 Baekje-daero, Duckjin-gu, \\ Jeonju, Jeonbuk 54896, Republic of Korea \\ ${ }^{3}$ Energetic Materials \& Pyrotechnics Department, Defence R\&D Center, Hanwha Corporation, 99 Oesam-ro-8-Beon-gil, \\ Yuseong-gu, Daejeon 34060, Republic of Korea \\ ${ }^{4}$ Advanced Propulsion Technology Center, The 4th R\&D Institute, Agency for Defense Development, Yoseong, \\ P.O. Box 35, Yuseong-gu, Daejeon 34186, Republic of Korea
}

Correspondence should be addressed to Jae-Hung Han; jaehunghan@kaist.ac.kr

Received 7 May 2016; Accepted 10 July 2016

Academic Editor: Evgeny Petrov

Copyright (C) 2016 Juho Lee et al. This is an open access article distributed under the Creative Commons Attribution License, which permits unrestricted use, distribution, and reproduction in any medium, provided the original work is properly cited.

\begin{abstract}
Pyrotechnic release devices such as explosive bolts are prevalent for many applications due to their merits: high reliability, high power-to-weight ratio, reasonable cost, and more. However, pyroshock generated by an explosive event can cause failures in electric components. Although pyroshock propagations are relatively well understood through many numerical and experimental studies, the prediction of pyroshock generation is still a very difficult problem. This study proposes a numerical method for predicting the pyroshock of a ridge-cut explosive bolt using a commercial hydrocode (ANSYS AUTODYN). A numerical model is established by integrating fluid-structure interaction and complex material models for high explosives and metals, including high explosive detonation, shock wave transmission and propagation, and stress wave propagation. To verify the proposed numerical scheme, pyroshock measurement experiments of the ridge-cut explosive bolts with two types of surrounding structures are performed using laser Doppler vibrometers (LDVs). The numerical analysis results provide accurate prediction in both the time (acceleration) and frequency domains (maximax shock response spectra). In maximax shock response spectra, the peaks due to vibration modes of the structures are observed in both the experimental and numerical results. The numerical analysis also helps to identify the pyroshock generation source and the propagation routes.
\end{abstract}

\section{Introduction}

In recent years, pyrotechnics have been prevalent in many applications due to its advantages: high reliability, high power-to-weight ratio, compact size, and reasonable cost [1]. In particular, pyrotechnics are employed in many release devices for aircraft, spacecraft, and missile applications. Widely used pyrotechnic release devices include explosive bolts, explosive separation nuts, clamp separators, rod separators, tension release devices, and ball release system $[1,2]$. However, an excessive shock level is the major disadvantage of the pyrotechnic systems. Pyroshock, also called pyrotechnic shock, is defined as the response of a structure to high frequency and high magnitude stress waves generated by an explosive event. Pyroshock is typically categorized as near-field, midfield, and far-field pyroshock based on the magnitude and spectral content [3]. Although pyroshock rarely damages structures themselves, it can easily cause failures or malfunctions in electric components [4]. Relay chatter and hard failures of small circuit components and short circuits by dislodging of contaminants are well-known failures of electric components by pyroshock.

To mitigate damage from pyroshock, many studies have attempted to understand the characteristics of pyroshock generation and propagation. However, the nature of explosive events makes it hard to accurately analyze or measure 
many important internal parameters, such as the pressure variations of explosives. Therefore, most previous studies on pyroshock during the past half century have focused on pyroshock propagation either in numerical or in experimental ways.

Pyroshock measurement technique has been well established and summarized in several standards $[3,5,6]$ and relevant reports [7-9]. Commercial accelerometers are normally utilized for pyroshock measurement despite some potential limitations. In particular, the resonance of accelerometers limits pyroshock measurements in the near field, which often has higher frequency content than the resonance frequency of the sensor. This problem can be avoided by using laser Doppler vibrometers [3, 10]. For pyroshock propagation experiments, many pyroshock simulation techniques have been proposed to avoid using explosives $[3,4,11]$. Mechanical impact is widely used to simulate pyroshock with reasonable cost and safety. However, pyrotechnical excitation using actual pyrotechnic devices should be used for near-field pyroshock study. Recently, pyroshock simulation technique using laser-induced shock was proposed [12-14].

For numerical analysis of pyroshock propagation, the finite element method (FEM) and the statistical energy analysis (SEA) method are widely used [11]. Although the FEM can handle stress wave propagation theoretically, FEM models become computationally intensive to accurately analyze high frequency structural modes [15]; FEM is effective in analyzing only low frequency dynamic loading on structures. For example, a previous study [16] reported a discrepancy in the high frequency range between FEM models and experiments although the FEM models accurately estimated shock propagation under $1000 \mathrm{~Hz}$. On the other hand, the SEA method is a general approach for high frequency vibroacoustic problems [3]. The SEA method has been extended in conjunction with virtual mode synthesis and simulation (VMSS) to predict the transient response of pyroshock [11, 17]. To handle midfrequency range accurately, a hybrid FEM/SEA approach has been proposed [18]. However, the SEA based method cannot predict pyroshock propagation for each specific point because its calculation is statistical and spatially averaged.

On the other hand, relatively few studies have reported on pyroshock generation. In many cases, it is extremely hard to measure experimental parameters at near-field pyroshock to understand pyroshock generation characteristics. For example, to protect against damage from detonation products and fragments, protective structures are necessary and they make it hard to use various optical sensors. Therefore, the numerical approach can be a good alternative. Although some studies $[3,11]$ have suggested that hydrocodes can be used to analyze pyroshock generation, it has not yet been fully established and verified. Hydrocodes were originally developed to solve problems under very fast and intense loading on structures [19]. They have been intensively used to solve impact problems of thick metal plates [20], composite structures [21, 22], space reentry vehicles [23, 24], and canopy of fighters [25]. Recent advances of hydrocodes include EulerLagrange interaction and complex material models for high explosives and solids. In the field of pyrotechnics, hydrocodes have been mainly used to analyze the separation mechanism without pyroshock prediction of pyrotechnic release devices: ridge-cut explosive bolts $[26,27]$, linear shaped charge [2830], expanding tubes [31], and more.

This study presents a numerical method to predict pyroshock of ridge-cut explosive bolts. To accurately predict pyroshock, blast loads on structures, interaction between structural parts, and the acceleration calculation procedure need to be carefully considered. To verify the numerical analysis method and results, the pyroshocks of ridge-cut explosive bolts with two types of surrounding structures were experimentally measured. The numerical and experimental results were compared and the characteristics of pyroshock including pyroshock generation source, propagation routes, and spectral components with surrounding structures were discussed based on both results.

\section{Ridge-Cut Explosive Bolts}

The ridge-cut explosive bolt shown in Figure 1, which was designed and manufactured by Agency for Defense Development (ADD) and Hanwha Corporation, was studied. This highly reliable ridge-cut explosive bolt has already been commercialized. Figure 2 shows a schematic diagram of the ridge-cut explosive bolts. The diameter and length of the bolt body were $1 / 2$ an inch $(12.7 \mathrm{~mm})$ and $70 \mathrm{~mm}$. An initiator filled with ZPP (zirconium-potassium perchlorate) was used to detonate high explosives (RDX and PETN) in conjunction with priming material (LA, Lead Azide). The assembly process was as follows: first, RDX was loaded into the bolt body. After that, a sleeve was assembled and PETN was loaded. Before the initiator was connected, Lead Azide was injected between the PETN and the initiator. The bolt body and the sleeve were made of $17-4 \mathrm{PH}$ stainless steel; the mass of RDX and PETN was approximately $120 \mathrm{mg}$ and $56 \mathrm{mg}$.

The separation mechanism of ridge-cut explosive bolts, also known as a ridge-cut mechanism, is well established $[26,27,32]$. Shock waves generated by the detonation of high explosives (RDX and PETN) reflect back as release waves at ridge-shaped structures. Due to the superposition or concentration of the release waves, high tensile stress is induced and failure occurs. The typical separation plane is depicted in Figure 2.

\section{Pyroshock Measurement of Ridge-Cut Explosive Bolts}

3.1. Experimental Setup. To measure the pyroshock of the ridge-cut explosive bolts, the ridge-cut explosive bolts were mounted onto a circular plate using fixtures as shown in Figure 3. Here, two types of circular plates were used: the thicknesses of the two plates were $22 \mathrm{~mm}$ and $32 \mathrm{~mm}$. The diameter of both the circular plates was $300 \mathrm{~mm}$. The fixture and the circular plates were made of structural carbon steel S45C. As shown in Figure 4, the pyroshock data were measured using three laser Doppler vibrometers (LDVs) in terms of velocities. The measurement points were located on the 


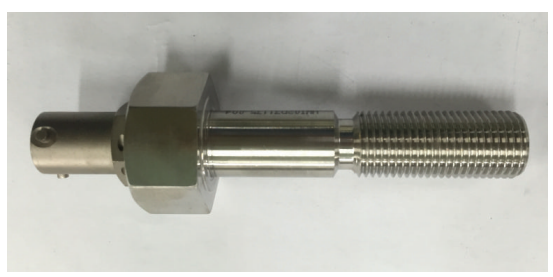

(a)

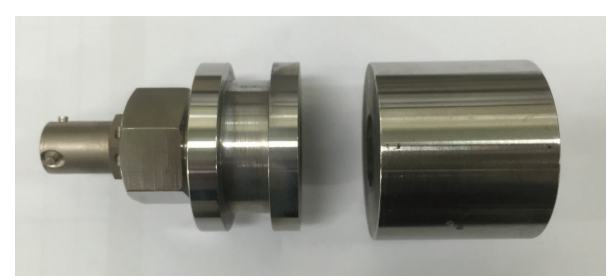

(b)

FIgURE 1: Ridge-cut explosive bolts (a) before separation and (b) after separation.
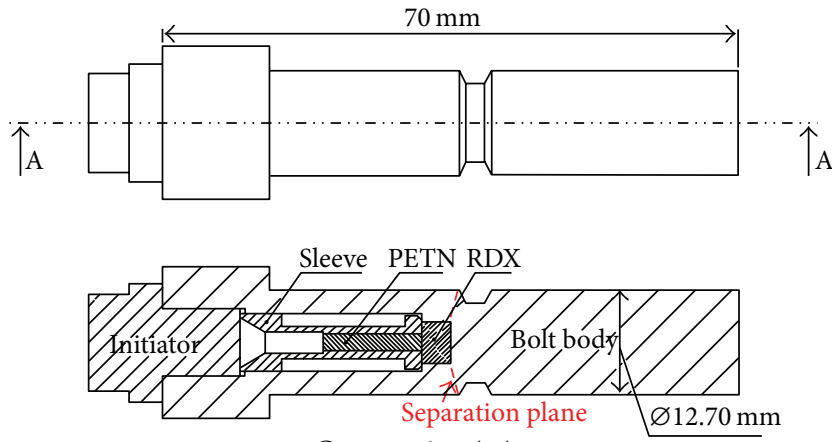

Cross section A-A

Figure 2: Diagram of the ridge-cut explosive bolts.

circular plates, respectively, $11 \mathrm{~mm}, 50 \mathrm{~mm}$, and $90 \mathrm{~mm}$ away from the center of the plates. In the LDV controllers, a band pass filter with a passing frequency from $100 \mathrm{~Hz}$ to $100 \mathrm{kHz}$ was applied; this filter was used to eliminate high frequency noise, aliasing, and low frequency data drift. To guarantee the accuracy of LDVs, a calibrator (Brüel \& Kajær's calibration exciter type 4294) was used to calibrate LDV signals. The processed signals from LDV controllers were acquired using a PC with an FPGA DAQ board. The sampling frequency and the sampling time were set to $1 \mathrm{MHz}$ and $30 \mathrm{~ms}$, respectively. Pyroshock measurement experiments were performed five times: three times for $22 \mathrm{~mm}$ thickness circular plates and two times for $22 \mathrm{~mm}$ thickness circular plates. All the other measurement details complied with the NASA standard [3].

3.2. Pyroshock Data Analysis. In most cases, an acceleration time history and its spectrum are used to describe pyroshock [3]. Among many spectra, the shock response spectra (SRS) are commonly used to evaluate pyroshock. SRS are graphs of the peak acceleration response of an array of a singledegree-of-freedom (SDOF) system that has different natural frequencies [33]. Therefore, SRS can be utilized to estimate the damage potential for electric components that have specific natural frequencies. The damping of each SDOF system is typically set to 0.05 . Depending on how the peak acceleration is chosen, SRS are categorized as positive, negative, primary, residual, and maximax SRS. Among them, maximax SRS, which envelop all other SRS, are commonly used for pyroshock quantification [3]. From the measured velocities, the acceleration time histories and maximax SRS were calculated. First, the 10th-order Butterworth band pass filter between $100 \mathrm{~Hz}$ and $100 \mathrm{kHz}$ was applied to the velocities. This filter has an attenuation slope of $60 \mathrm{~dB} /$ octave, which satisfies the requirement of the NASA standard [3]. The acceleration was calculated by differentiating velocities in time. From the acceleration, maximax SRS were calculated using open-source MATLAB codes [33].

The measured acceleration from experiment 1 (the $22 \mathrm{~mm}$ thickness circular plate) and experiment 4 (the $32 \mathrm{~mm}$ thickness circular plate) is plotted up to $5 \mathrm{~ms}$ in Figure 5. At the $11 \mathrm{~mm}$ point, the maximum peak-to-peak acceleration was around $240 \mathrm{kG}$ for the $22 \mathrm{~mm}$ thickness and $130 \mathrm{kG}$ for the $32 \mathrm{~mm}$ thickness. At the $50 \mathrm{~mm}$ point, the maximum peak-topeak acceleration was around $70 \mathrm{kG}$ for the $22 \mathrm{~mm}$ thickness and $55 \mathrm{kG}$ for the $32 \mathrm{~mm}$ thickness. At the $90 \mathrm{~mm}$ point, the maximum peak-to-peak acceleration was around $60 \mathrm{kG}$ for the $22 \mathrm{~mm}$ thickness and $50 \mathrm{kG}$ for the $32 \mathrm{~mm}$ thickness. Thus, the pyroshock level can significantly vary depending on the shape of the mounting structures. In particular, a thinner structure has higher pyroshock level when the same pyrotechnic devices are used.

The maximax SRS from $1 \mathrm{kHz}$ to $100 \mathrm{kHz}$ are presented in Figure 6. These results show that although the same pyrotechnic devices and structures were used, the pyroshock level varied. However, the averaged maximax SRS for each thickness (Figure 6(c)) clearly showed that thinner structure had a higher SRS level at each point for most frequency ranges. The characteristics of the measured pyroshock results will be discussed in detail later.

\section{Numerical Analysis Methodology}

Hydrocode can be used for pyroshock prediction of the ridgecut explosive bolts or similar pyrotechnic release devices, because it enables fluid-structure interaction (FSI) analysis and complex material modeling for high explosives and metals. FSI is necessary for analyzing shock wave transmission from the high explosives to the metals and the pressure on the structure from the detonation products. Complex material models are necessary for the high explosive detonation, shock wave transmission, and shock wave propagation in metals and high explosives. The numerical analysis method for the separation mechanism of ridge-cut explosive bolts using hydrocodes has been well established in previous studies $[26,27]$. The numerical analysis method is summarized and the modification for pyroshock prediction is introduced here. 


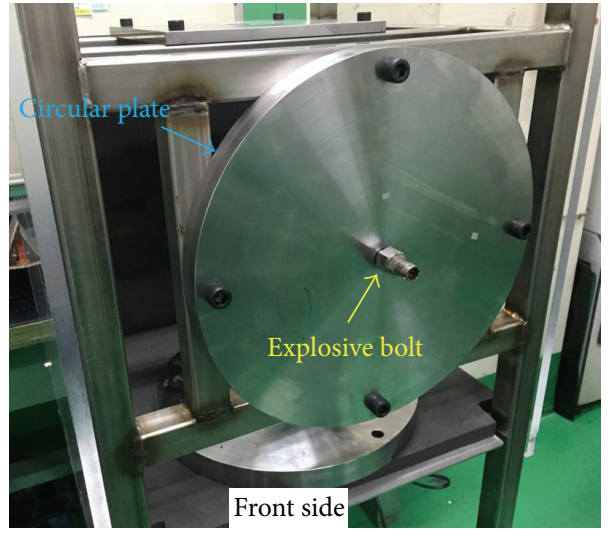

(a)

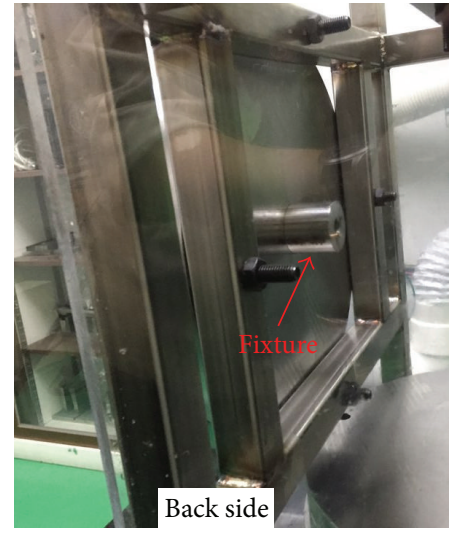

(b)

FIGURE 3: Pyroshock measurement structure setup using a fixture and a circular plate, (a) front side and (b) back side.

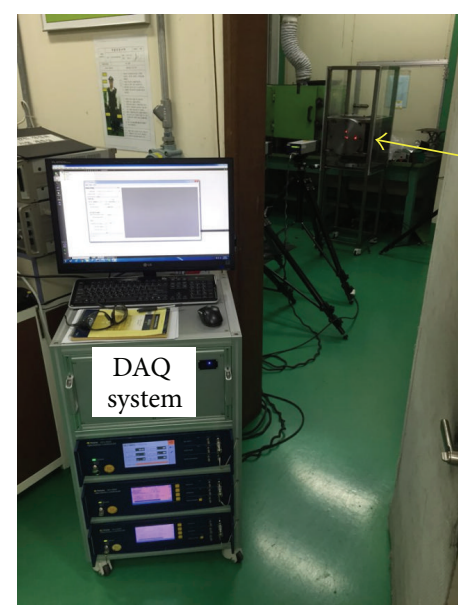

(a)

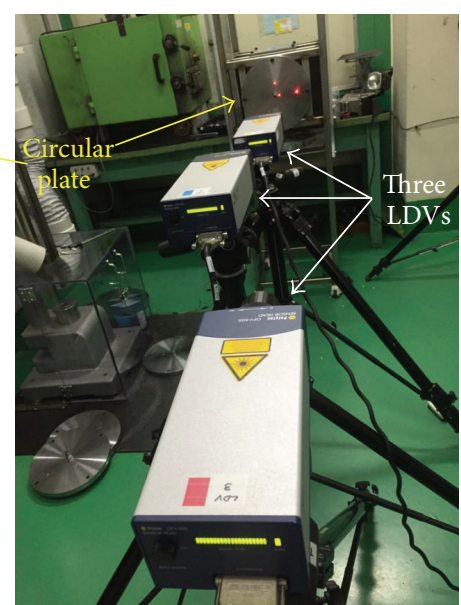

(b)

Figure 4: Experimental setup for pyroshock measurement: (a) DAQ system and (b) three LDVs.

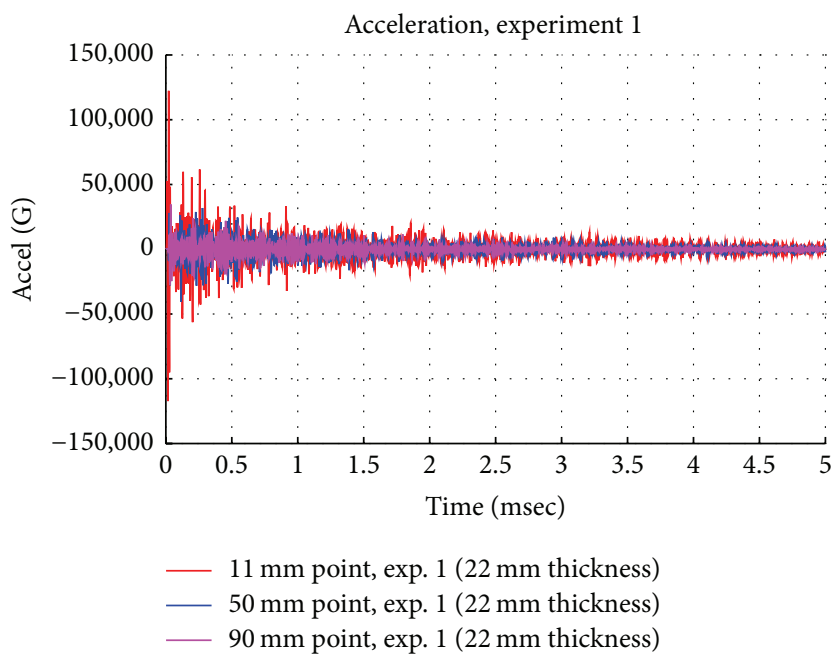

(a)

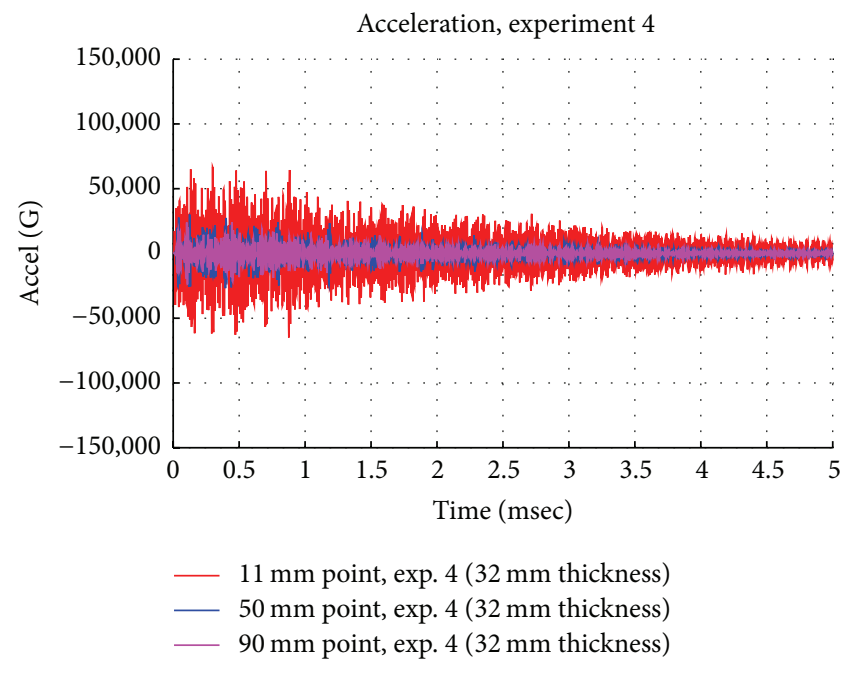

(b)

FIGURE 5: Measured pyroshock in terms of acceleration: (a) experiment 1 (the $22 \mathrm{~mm}$ thickness circular plate) and (b) experiment 4 (the $32 \mathrm{~mm}$ thickness circular plate). 

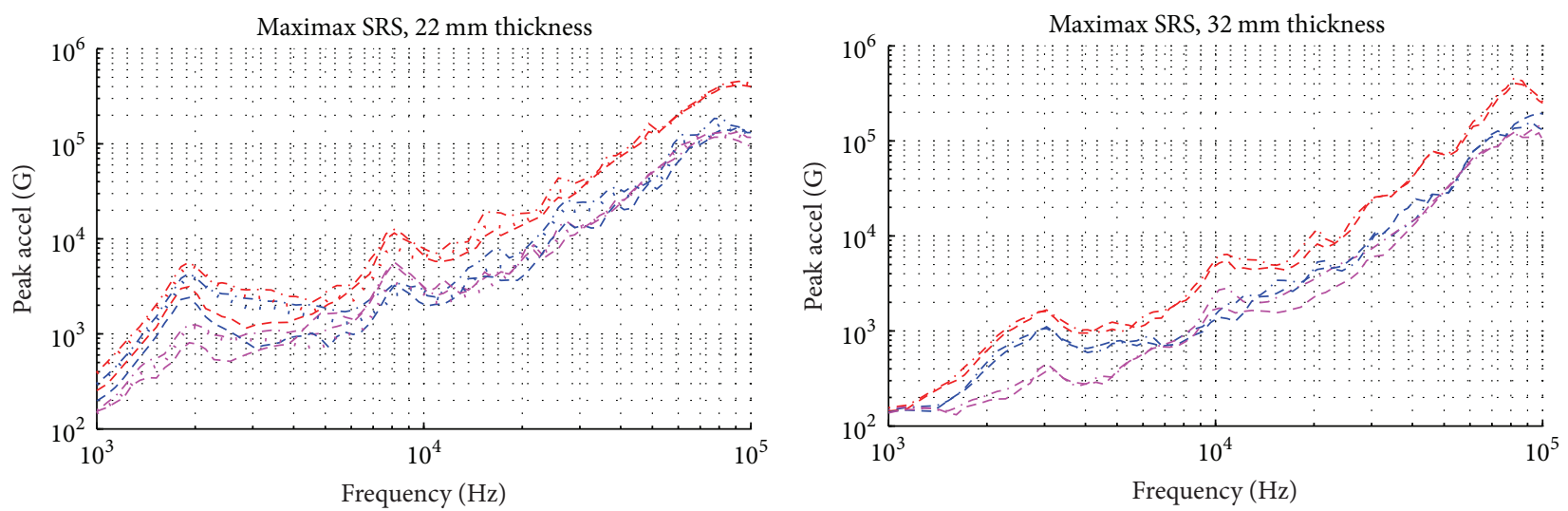

\begin{tabular}{|c|c|}
\hline$-\cdots 11 \mathrm{~mm}$ point, exp. 1 & $---90 \mathrm{~mm}$ point, exp. 2 \\
\hline -. $50 \mathrm{~mm}$ point, exp. 1 & ..... $11 \mathrm{~mm}$ point, exp. 3 \\
\hline $90 \mathrm{~mm}$ point, exp. 1 & … $50 \mathrm{~mm}$ point, exp. 3 \\
\hline $11 \mathrm{~mm}$ point, exp. 2 & ...... $90 \mathrm{~mm}$ point, exp. 3 \\
\hline
\end{tabular}

(a)

$$
\begin{aligned}
& \text { _. - } 11 \mathrm{~mm} \text { point, exp. } 4 \quad \text { _ - } 11 \mathrm{~mm} \text { point, exp. } 5 \\
& \text {-.- } 50 \mathrm{~mm} \text { point, exp. } 4 \quad \text { - }-50 \mathrm{~mm} \text { point, exp. } 5 \\
& \text { _. } 90 \mathrm{~mm} \text { point, exp. } 4 \quad \text { - - } 90 \mathrm{~mm} \text { point, exp. } 5
\end{aligned}
$$

(b)

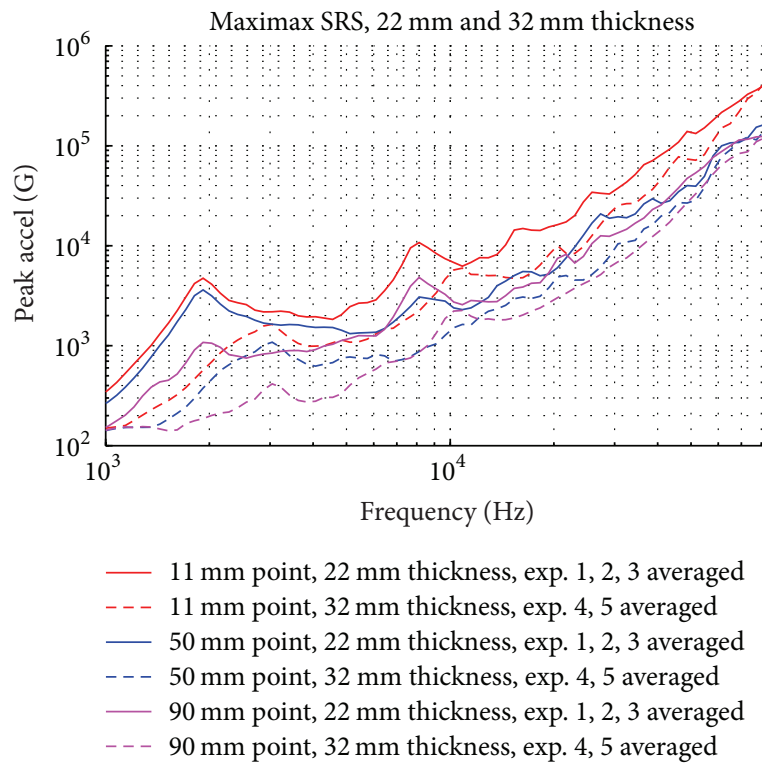

(c)

FIGURE 6: Measured pyroshock in terms of maximax SRS: (a) experiments 1, 2, and 3 (the $22 \mathrm{~mm}$ thickness circular plate) and (b) experiments 4 and 5 (the $32 \mathrm{~mm}$ thickness circular plate). (c) Averaged results for the $22 \mathrm{~mm}$ thickness circular plate and the $32 \mathrm{~mm}$ thickness circular plate.

4.1. Summary of the Numerical Analysis Method. In this study, a commercial hydrocode (ANSYS AUTODYN) was used. To reduce computational cost, $2 \mathrm{D}$ axisymmetric analyses were performed. Some modeling parts, including material models, geometry, structure mesh, structural boundary condition, connections, and body interactions between solid bodies were modeled in ANSYS Workbench environment. The material models will be discussed in the next section. Geometric modeling of the bolt body, the fixture, the sleeve, and the initiator with a $22 \mathrm{~mm}$ thickness circular plate and a $32 \mathrm{~mm}$ thickness circular plate was performed separately as shown in Figure 7. The structural mesh of the bolt body, the sleeve, the initiator, and the fixture was constructed with Quad 4 elements in a $0.2 \mathrm{~mm}$ size. The maximum aspect ratio of this structure mesh was around 2. Uniformly mapped meshes with a $0.5 \mathrm{~mm}$ element size were prepared for the circular plates. The constructed mesh of the ridge-cut explosive bolts with a $22 \mathrm{~mm}$ thickness circular plate is shown in Figure 8. A fixed support boundary condition in $x$-and $y$-direction was applied at upper line of the circular plates as shown in Figure 7. No boundary conditions were applied to the axis of symmetry. All screw thread connections were modeled as a single body (merged). These included the thread between the bolt body and the fixture, the bolt body and the sleeve, 


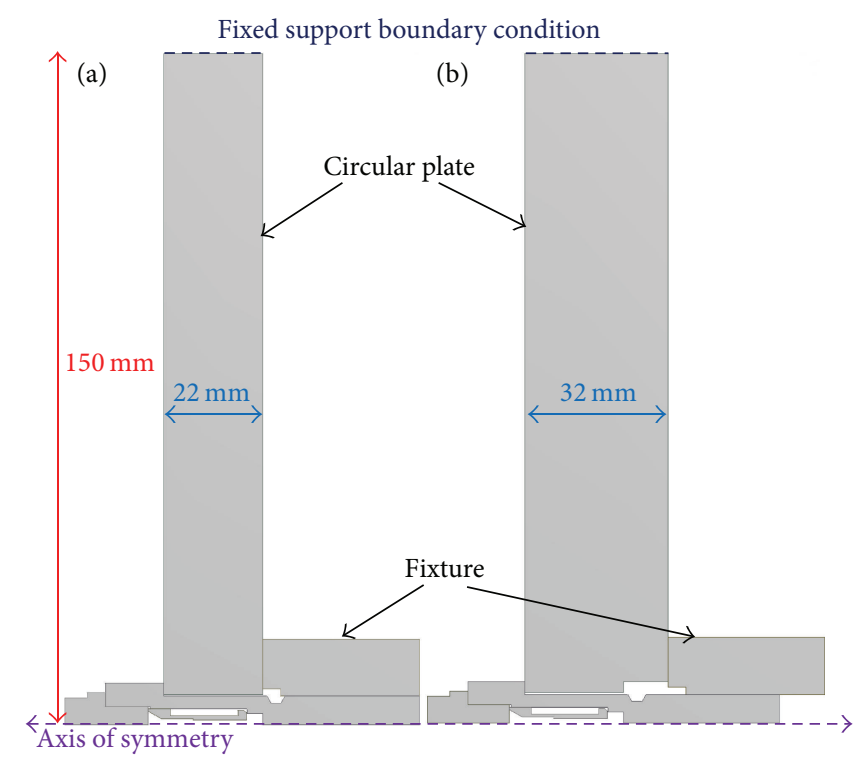

FIGURE 7: Geometric modeling and structure boundary condition of the bolt body, fixture, sleeve, and initiator with (a) the $22 \mathrm{~mm}$ thickness circular plate and (b) the $32 \mathrm{~mm}$ thickness circular plate.

and the bolt body and the initiator. Other contacts were considered as frictional interaction with a 0.13 static friction coefficient and a 0.12 kinetic friction coefficient.

Euler part modeling was performed in ANSYS AUTODYN, as shown in Figure 9; the Euler-Lagrange interaction was considered. The size of the Euler elements was chosen as $0.1 \mathrm{~mm}$, half of the size of structural mesh for the bolt body and so on. Only high explosives (RDX and PETN) were modeled because pyroshocks generated by an initiator (ZPP) and LA are negligible. The remaining area was filled with air. A flow-out boundary condition was applied at the boundary of the Euler part except for the axis of symmetry. The point of detonation initiation was defined at the end of the PETN located on the axis of symmetry as depicted in Figure 9. The gauge points to estimate the pyroshock results were defined on the circular plates. These points were located on left surface of the circular plates; they were, respectively, $11 \mathrm{~mm}, 50 \mathrm{~mm}$, and $90 \mathrm{~mm}$ distant from the axis of symmetry as the measurement points were chosen in the experiments. The numerical analyses were performed up to $1 \mathrm{~ms}$. To reduce computational cost, the Euler parts were analyzed only up to $0.01 \mathrm{~ms}$. Time course plots of the total energy for the Euler parts clearly showed that most of the energy of the Euler parts was transmitted to the Lagrange parts before $0.01 \mathrm{~ms}$. After $0.01 \mathrm{~ms}$, only the Lagrange parts were analyzed. The time steps were determined by the CFL condition for a stable and accurate solution. The time step safety factor was defined as 0.6 and 0.9 for before and after $0.01 \mathrm{~ms}$, respectively.

4.2. Material Modeling. In hydrocode, material models that define the relationship between stress, deformation, and internal energy are necessary. For fluid, the above relationship can be simplified as the relationship between the pressure, specific volume, and specific energy due to the lack of shear stiffness. This relation is an equation of state (EOS). On the other hand, material models for a solid should include the shear modulus, yield criteria, and failure criteria.

In this study, the shock EOS was used for metals to model shock wave propagation:

$$
P-P_{H}=\frac{\gamma}{v}\left(e-e_{H}\right)
$$

where $P$ is the pressure, $v$ is the specific volume, and $e$ is the specific internal energy. $\gamma$ is the Gruneisen constant, which can be estimated experimentally or theoretically. The shock EOS is a Mie-Gruneisen form of EOS [34] that uses Hugoniot (subscript $H$ ), the experimentally determined locus of all shocked states for each metal, as reference. The Hugoniot can be expressed in several ways and is transferable [35]. The Hugoniot between the shock velocity $U$ and the particle velocity $u$ is useful and easily understandable. For most metals, they are linearly related and can be estimated experimentally $[34,35]$ :

$$
U=C_{0}+s u \text {. }
$$

For yield criteria, the Johnson-Cook empirical equation [36] was used:

$$
Y=\left(\sigma_{0}+B \varepsilon^{n}\right)\left(1+C \ln \frac{\dot{\varepsilon}}{\dot{\varepsilon}_{0}}\right)\left[1-\left(\frac{T-T_{r}}{T_{m}-T_{r}}\right)^{m}\right],
$$

where $Y$ is the yield stress, $\varepsilon$ is the strain, $\dot{\varepsilon}$ is the strain rate, $\dot{\varepsilon}_{0}$ is the reference strain rate, $T$ is the temperature, $T_{r}$ is the reference temperature, and $T_{m}$ is the melting point. Other empirical parameters $\left(\sigma_{0}, B, n, C, m\right)$ have to be experimentally determined. This empirical constitutive model is widely used because it can predict plastic deformation under a large strain, high strain rate, and high temperature.

To model the separation mechanism of ridge-cut explosive bolts, a principal stress failure model was proposed in previous studies [26, 27]. To prevent calculation failure due to a large distortion of the Lagrange elements, an erosion model was used as well.

The bolt body and the sleeve were made of $17-4 \mathrm{PH}$ stainless steel. The initiator was modeled as a solid structure with 17-4PH stainless steel. The fixture and the circular plates were made of structural carbon steel S45C. The material properties for $17-4 \mathrm{PH}$ stainless steel were well estimated in a previous study [27]. However, the material properties for structural carbon steel S45C are unknown. Therefore, the properties pertaining to steel 1006 were used in this study. Steel 1006 is the only structural carbon steel for which the material properties for hydrocode are known. Neither a failure model nor an erosion model was applied to steel 1006 , because failure and large distortion would not occur in circular plates. The material properties of these metals are summarized in Table 1.

For high explosives (RDX and PETN), the Jones-WilkinsLee (JWL) EOS [37] was utilized:

$$
P=A\left(1-\frac{\omega \eta}{R_{1}}\right) e^{-R_{1} / \eta}+B\left(1-\frac{\omega \eta}{R_{2}}\right) e^{-R_{2} / \eta}+\omega \rho e,
$$




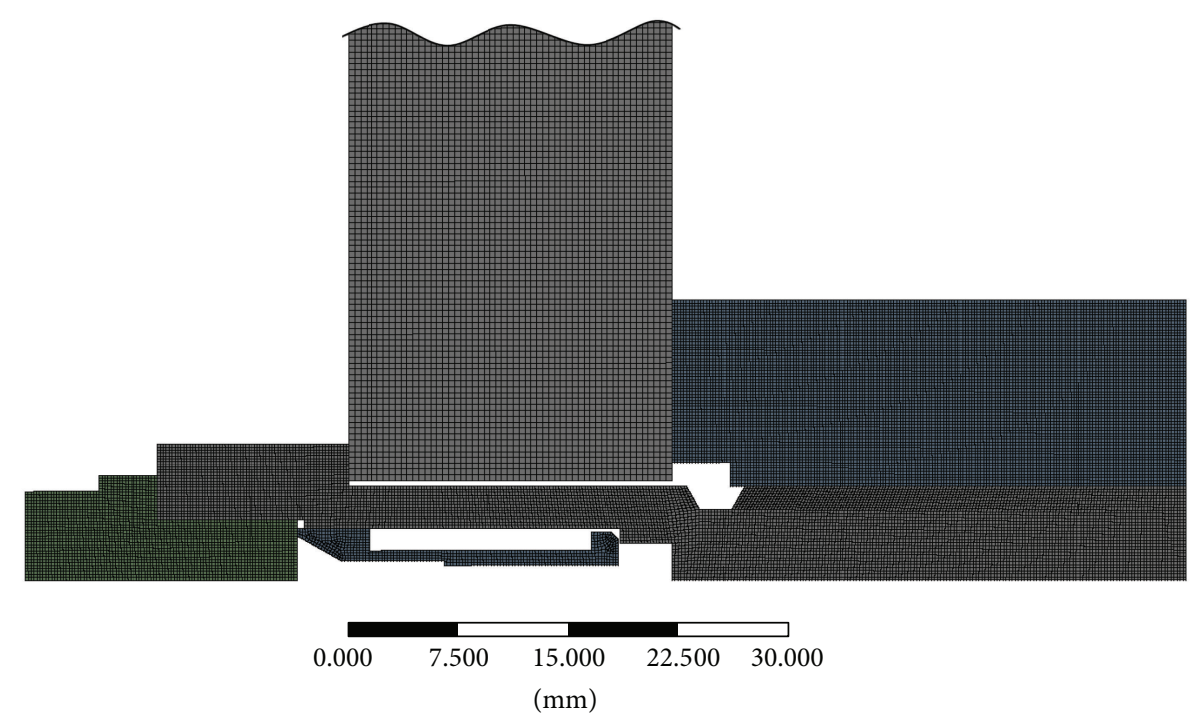

FIgURE 8: Meshing of the ridge-cut explosive bolts and the $22 \mathrm{~mm}$ thickness circular plate.

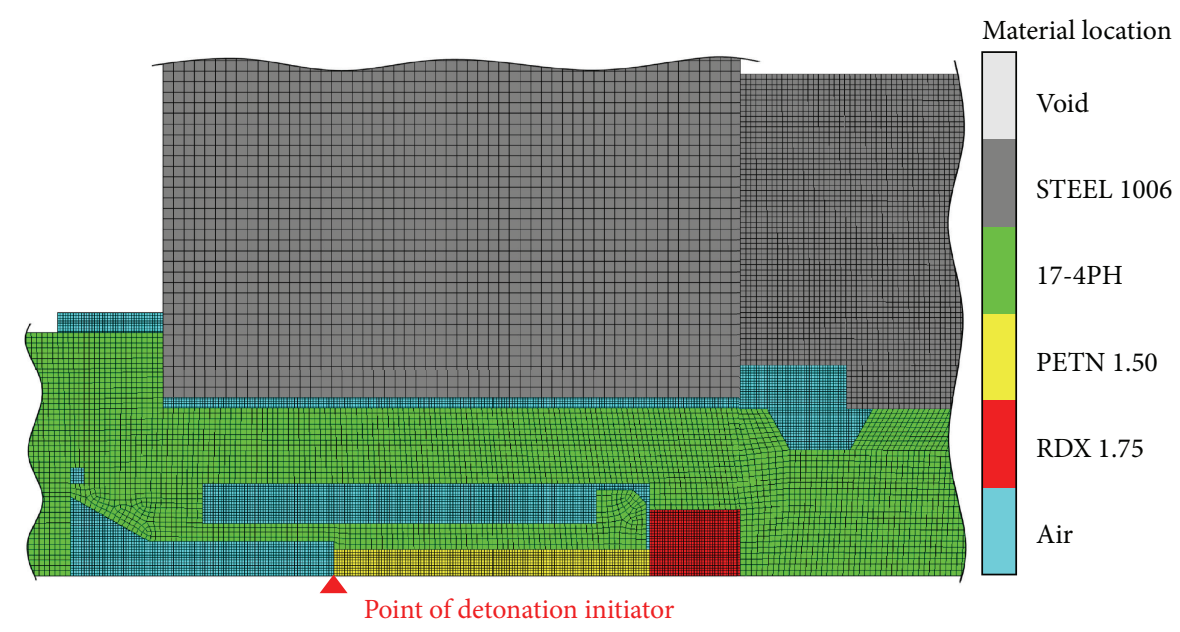

FIGURE 9: Euler part modeling for air, RDX, and PETN.

where $P$ is the pressure and $\rho$ is the density and $\eta$ is the relative density $\rho / \rho_{0}$ and $e$ is the specific internal energy. Other empirical parameters $\left(A, B, R_{1}, R_{2}, \omega\right)$ had to be determined from the detonation experiments. This model can estimate parameters of detonation products from the initial state to large expansion states. The Chapman-Jouguet (C-J) point where the detonation is complete is the initial state for a JWL EOS. For the shock propagation modeling in high explosives, the detonation velocities are needed as well.

From the mass and the volume of high explosives (RDX and PETN), the densities can be calculated as $1.75 \mathrm{~g} / \mathrm{cm}^{3}$ for RDX and $1.50 \mathrm{~g} / \mathrm{cm}^{3}$ for PETN, approximately. Unlike the material properties of PETN $1.50 \mathrm{~g} / \mathrm{cm}^{3}$, the material properties of RDX $1.75 \mathrm{~g} / \mathrm{cm}^{3}$ are unknown. Therefore, the material properties of RDX $1.75 \mathrm{~g} / \mathrm{cm}^{3}$ were estimated from RDX $1.65 \mathrm{~g} / \mathrm{cm}^{3}$ using the authors' estimation method that was proposed in [27] and is only applicable with a slight variation in density. The material properties of high explosives are summarized in Table 2.

4.3. Pyroshock Prediction. The velocity results at the gauge points from the numerical analysis were used to predict pyroshock. To compare the analysis results with the experiments, these gauge points were assigned on the left surface of circular plates with $11 \mathrm{~mm}, 50 \mathrm{~mm}$, and $90 \mathrm{~mm}$ distance from the axis of symmetry as depicted in Figure 10. At these points, only normal velocities of the surfaces were extracted. In hydrocode, the variable time step was around several nanoseconds for the proposed models. By cubic spline interpolations, the velocities with constant time steps $(1 \mu \mathrm{s})$ were obtained: the sampling frequency was $1 \mathrm{MHz}$, the same as in the experiments. The 10th-order Butterworth band pass 
TABLE 1: Material properties of metals (17-4PH stainless steel, steel 1006).

\begin{tabular}{|c|c|c|c|}
\hline & & $17-4 \mathrm{PH}$ stainless steel & Steel 1006 \\
\hline \multicolumn{4}{|l|}{ Parameter of shock EOS } \\
\hline Density $\rho_{0}$ & $\left(\mathrm{~g} / \mathrm{cm}^{3}\right)$ & 7.81 & 7.896 \\
\hline Gruneisen coefficient $\gamma$ & (None) & 1.36 & 2.17 \\
\hline Empirical parameter $C_{0}$ & $(\mathrm{~m} / \mathrm{s})$ & 4550 & 4569 \\
\hline Empirical parameter $s$ & (None) & 1.41 & 1.49 \\
\hline Reference temperature $T_{r}$ & $(\mathrm{~K})$ & 295.15 & 295.15 \\
\hline Specific heat $C_{v}$ & $(\mathrm{~J} / \mathrm{kg} \mathrm{K})$ & 460 & 452 \\
\hline \multicolumn{4}{|l|}{ Parameter of Johnson-Cook strength model } \\
\hline Shear modulus & $(\mathrm{kPa})$ & $7.7437 \times 10^{7}$ & $8.18 \times 10^{7}$ \\
\hline Static yield stress $\sigma_{0}$ & $(\mathrm{kPa})$ & $1.172 \times 10^{6}$ & $3.5 \times 10^{5}$ \\
\hline Hardening constant $B$ & $(\mathrm{kPa})$ & $4.935 \times 10^{5}$ & $2.75 \times 10^{5}$ \\
\hline Hardening exponent $n$ & (None) & 0.22 & 0.36 \\
\hline Strain rate constant $C$ & (None) & 0.013 & 0.022 \\
\hline Thermal softening exponent $m$ & (None) & 1.015 & 1.0 \\
\hline Melting point $T_{m}$ & $(\mathrm{~K})$ & 1778 & 1811 \\
\hline Reference strain rate $\dot{\varepsilon}_{0}$ & (None) & 1.0 & 1.0 \\
\hline \multicolumn{4}{|l|}{ Parameter of principal stress failure model } \\
\hline Critical value of normal tensile stress $\sigma_{c}$ & $(\mathrm{kPa})$ & $2.8 \times 10^{6}$ & N/A \\
\hline \multicolumn{4}{|l|}{ Parameter of geometric strain erosion model } \\
\hline Erosion strain & (None) & 1.5 & N/A \\
\hline
\end{tabular}

TABLE 2: Material properties of high explosives (RDX 1.75, PETN $1.50)$.

\begin{tabular}{lccc}
\hline Parameter of JWL EOS & & RDX 1.75 & PETN 1.50 \\
\hline Density $\rho_{0}$ & $\left(\mathrm{~g} / \mathrm{cm}^{3}\right)$ & 1.75 & 1.50 \\
Parameter $A$ & $(\mathrm{kPa})$ & $7.108 \times 10^{8}$ & $6.253 \times 10^{8}$ \\
Parameter $B$ & $(\mathrm{kPa})$ & $1.222 \times 10^{7}$ & $2.329 \times 10^{7}$ \\
Parameter $R_{1}$ & $(\mathrm{None})$ & 4.4 & 5.25 \\
Parameter $R_{2}$ & $($ None $)$ & 1.2 & 1.6 \\
Parameter $\omega$ & $(\mathrm{None})$ & 0.32 & 0.28 \\
Detonation velocity $D$ & $(\mathrm{~m} / \mathrm{s})$ & $8.633 \times 10^{3}$ & $7.45 \times 10^{3}$ \\
C-J energy per unit volume $E_{0}\left(\mathrm{~kJ} / \mathrm{m}^{3}\right)$ & $9.45 \times 10^{6}$ & $8.56 \times 10^{6}$ \\
C-J pressure & $(\mathrm{kPa})$ & $3.419 \times 10^{7}$ & $2.2 \times 10^{7}$ \\
\hline
\end{tabular}

filter between $100 \mathrm{~Hz}$ and $100 \mathrm{kHz}$ was applied. The velocities were differentiated to obtain the acceleration. Finally, the maximax SRS were calculated.

\section{Pyroshock Prediction of Ridge-Cut Explosive Bolts}

5.1. Comparison with Experiments. The predicted pyroshock from the numerical analysis was compared with the experimental results in terms of acceleration and maximax SRS as shown in Figures 11 and 12. These comparisons clearly show that the numerical analysis results provide accurate predictions both in the time and in the frequency domains. In the time domain, the predicted pyroshock graphs had very similar shape and envelope for each experiment at every

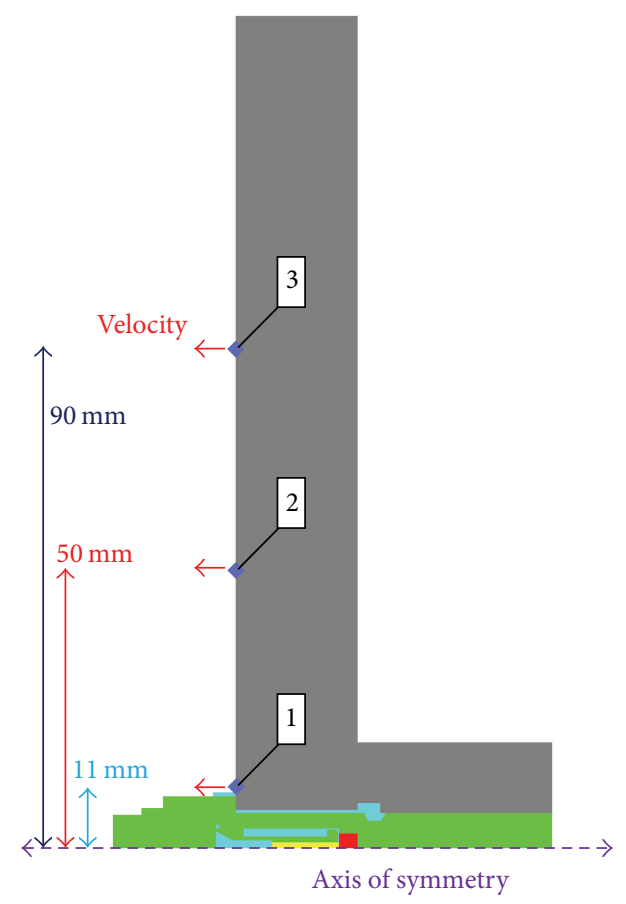

FIgURE 10: Position of gauges for pyroshock prediction.

measurement point up to $1 \mathrm{~ms}$. In maximax SRS, the numerical analysis results well estimate the magnitude, slope, and peaks. Considering the variations between experiments with the same conditions, the numerical predictions are suitable for early design processes when the experimental results 


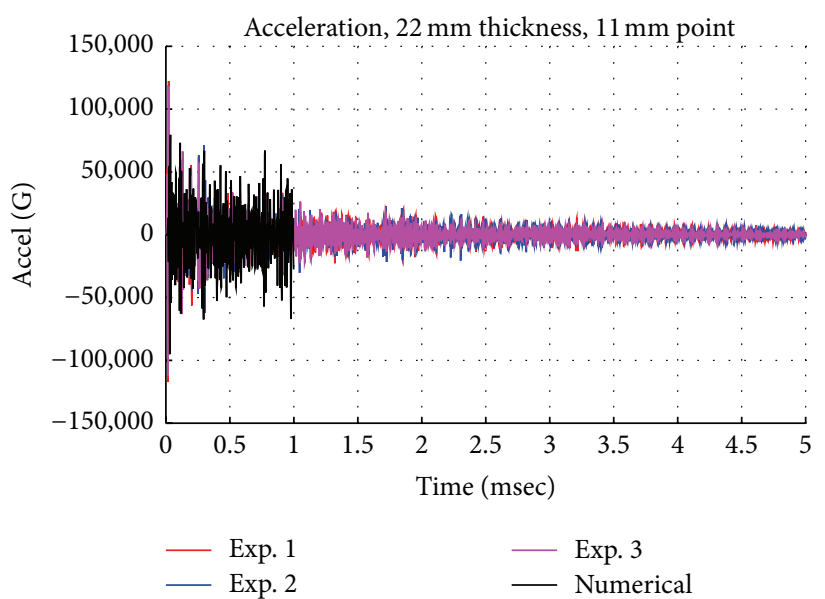

(a)

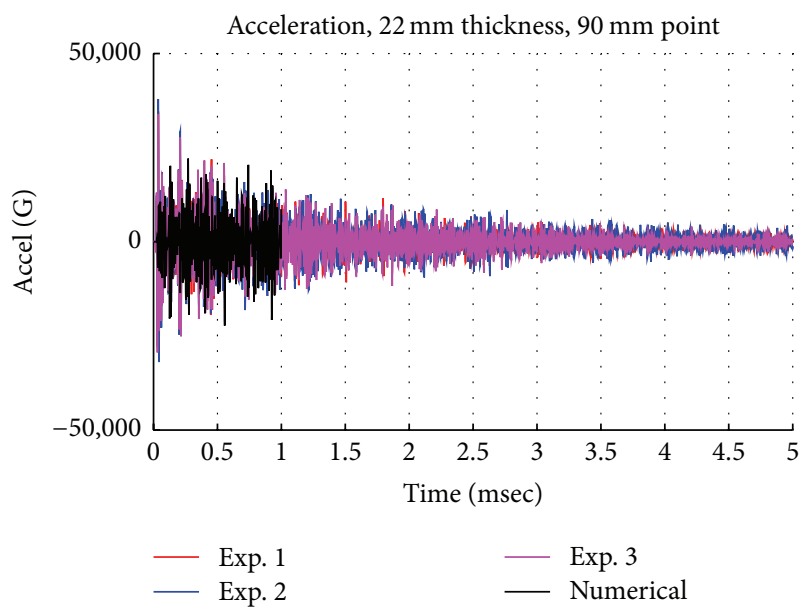

(c)

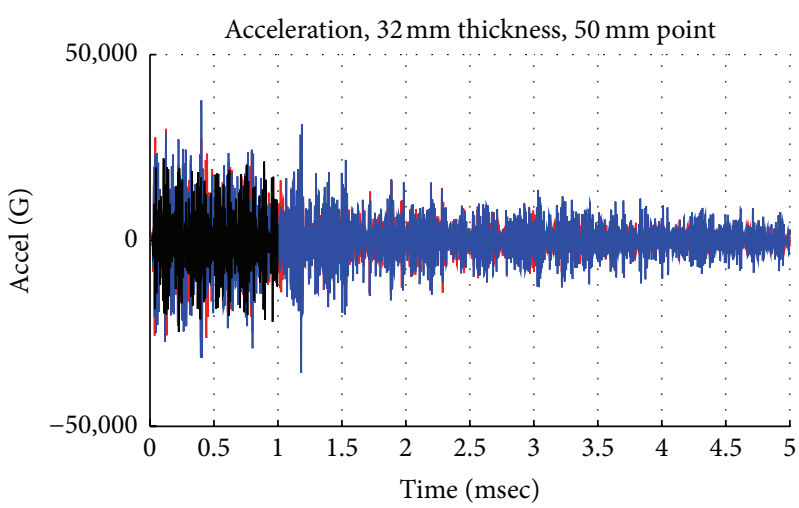

- Exp. 4

_ Numerical

(e)

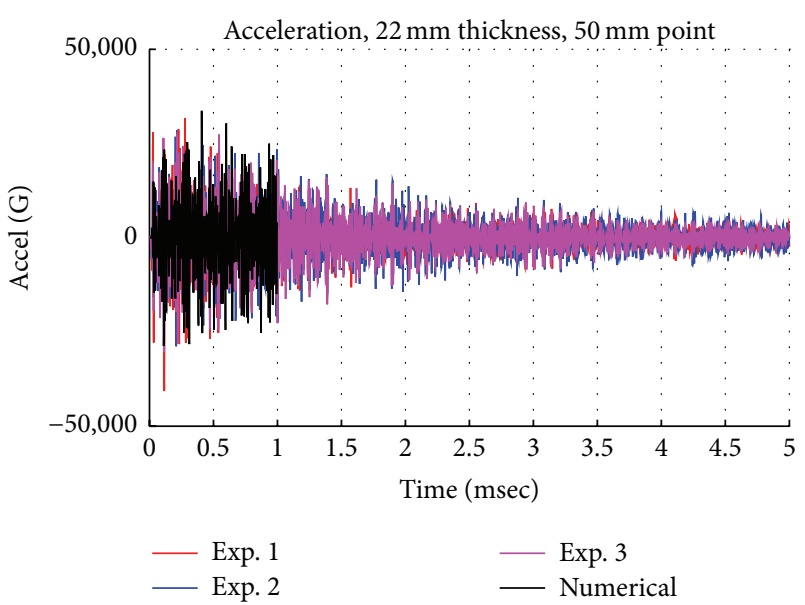

(b)

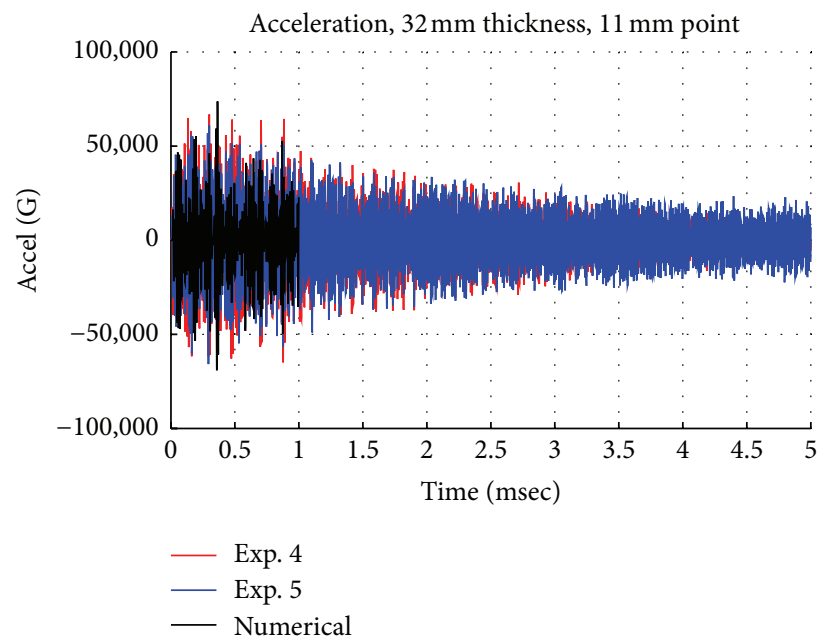

(d)

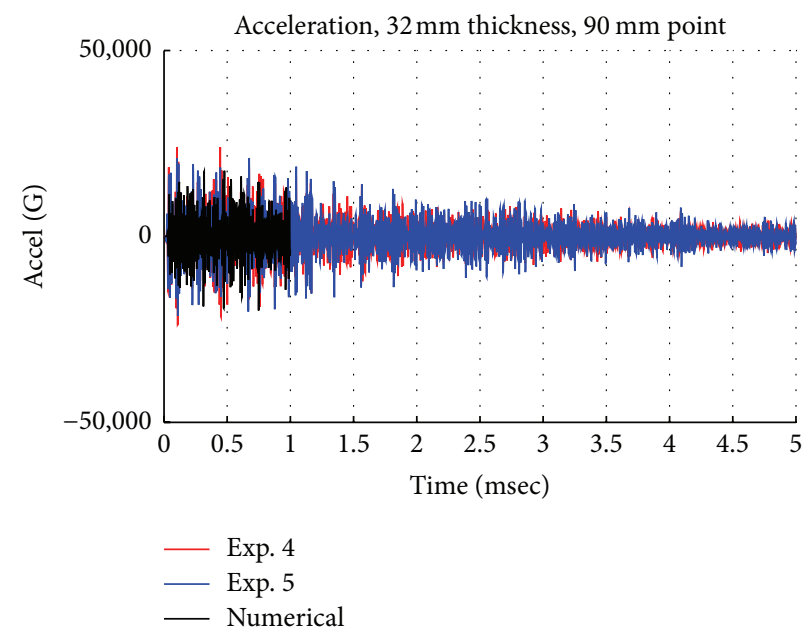

(f)

FIGURE 11: Comparison of acceleration between the numerical analysis and the experiments: (a) $11 \mathrm{~mm}$ point at a $22 \mathrm{~mm}$ thickness circular plate, (b) $50 \mathrm{~mm}$ point at a $22 \mathrm{~mm}$ thickness circular plate, (c) $90 \mathrm{~mm}$ point at a $22 \mathrm{~mm}$ thickness circular plate, (d) $11 \mathrm{~mm}$ point at a $32 \mathrm{~mm}$ thickness circular plate, (e) $50 \mathrm{~mm}$ point at a $32 \mathrm{~mm}$ thickness circular plate, and (f) $90 \mathrm{~mm}$ point at a $32 \mathrm{~mm}$ thickness circular plate. 


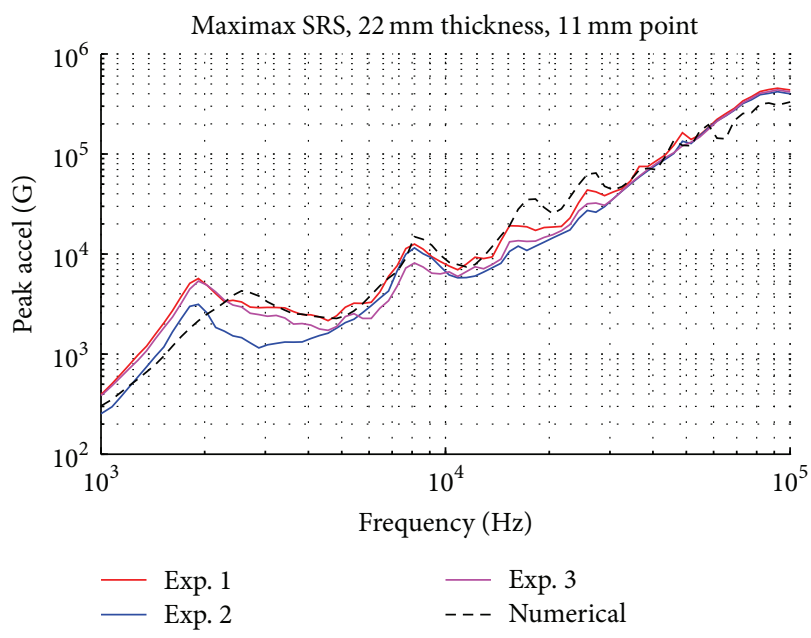

(a)

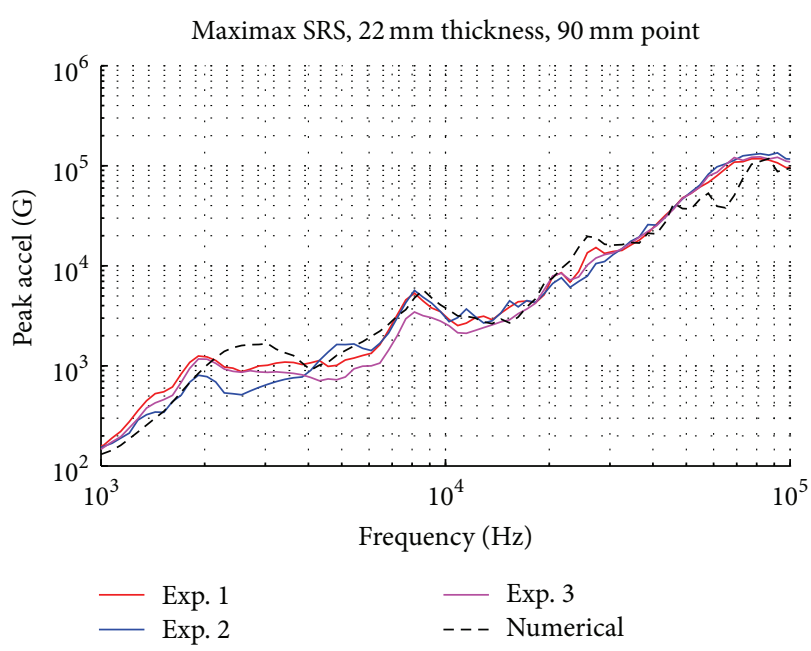

(c)

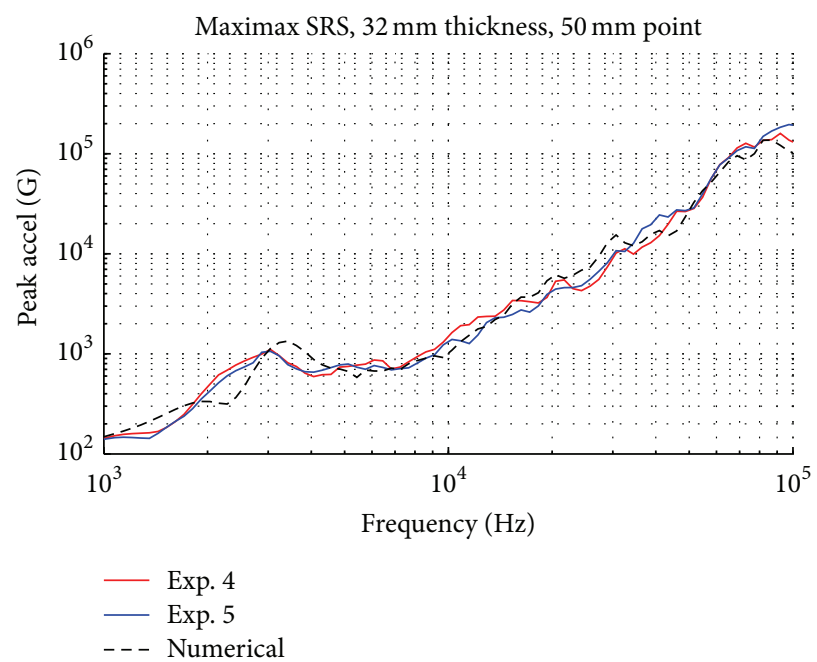

(e)

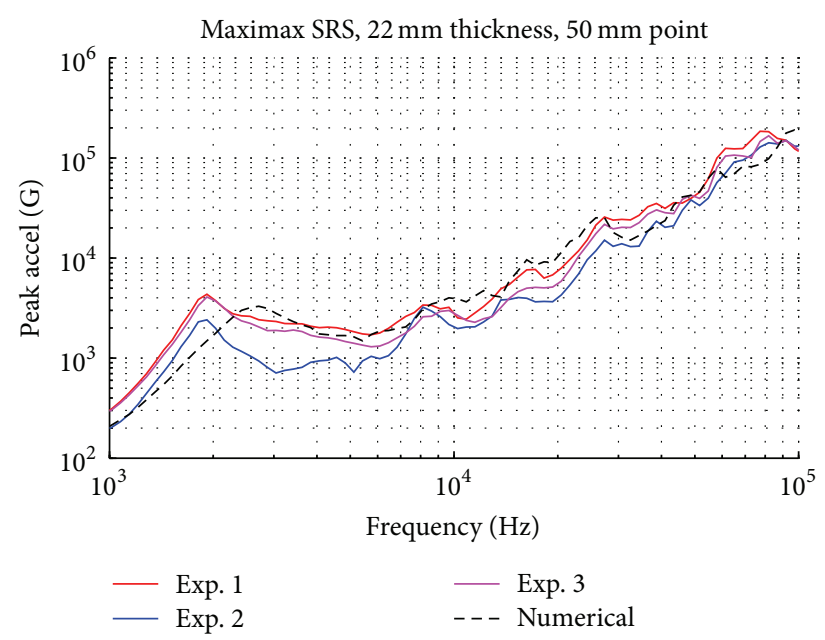

(b)

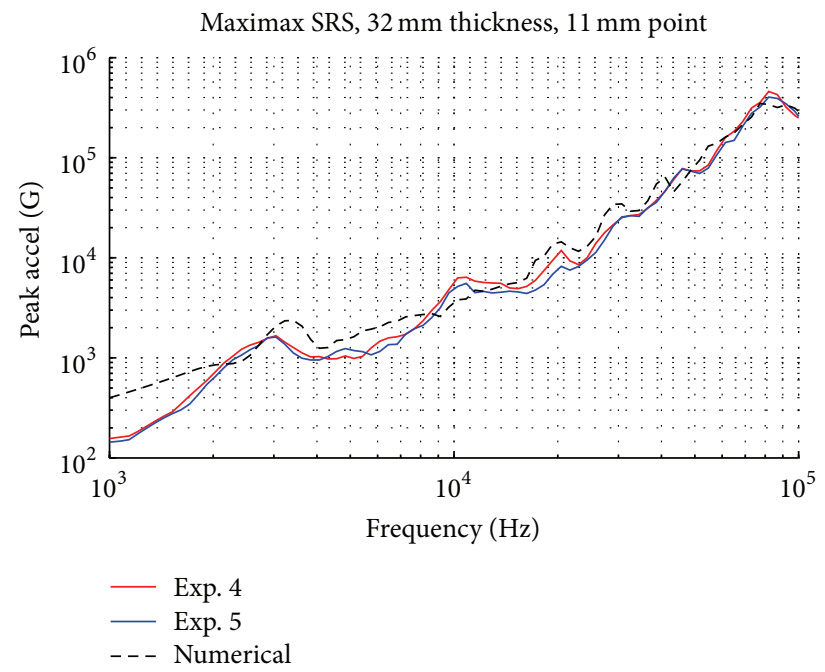

(d)

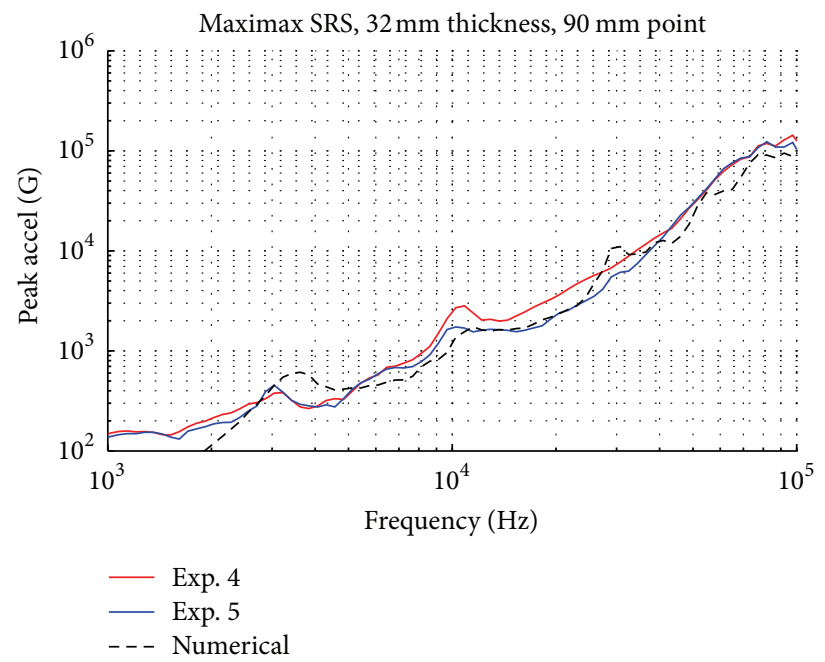

(f)

FIGURE 12: Comparison of maximax SRS between the numerical analysis and the experiments: (a) $11 \mathrm{~mm}$ point at a $22 \mathrm{~mm}$ thickness circular plate, (b) $50 \mathrm{~mm}$ point at a $22 \mathrm{~mm}$ thickness circular plate, (c) $90 \mathrm{~mm}$ point at a $22 \mathrm{~mm}$ thickness circular plate, (d) $11 \mathrm{~mm}$ point at a $32 \mathrm{~mm}$ thickness circular plate, (e) $50 \mathrm{~mm}$ point at a $32 \mathrm{~mm}$ thickness circular plate, and (f) $90 \mathrm{~mm}$ point at a $32 \mathrm{~mm}$ thickness circular plate. 

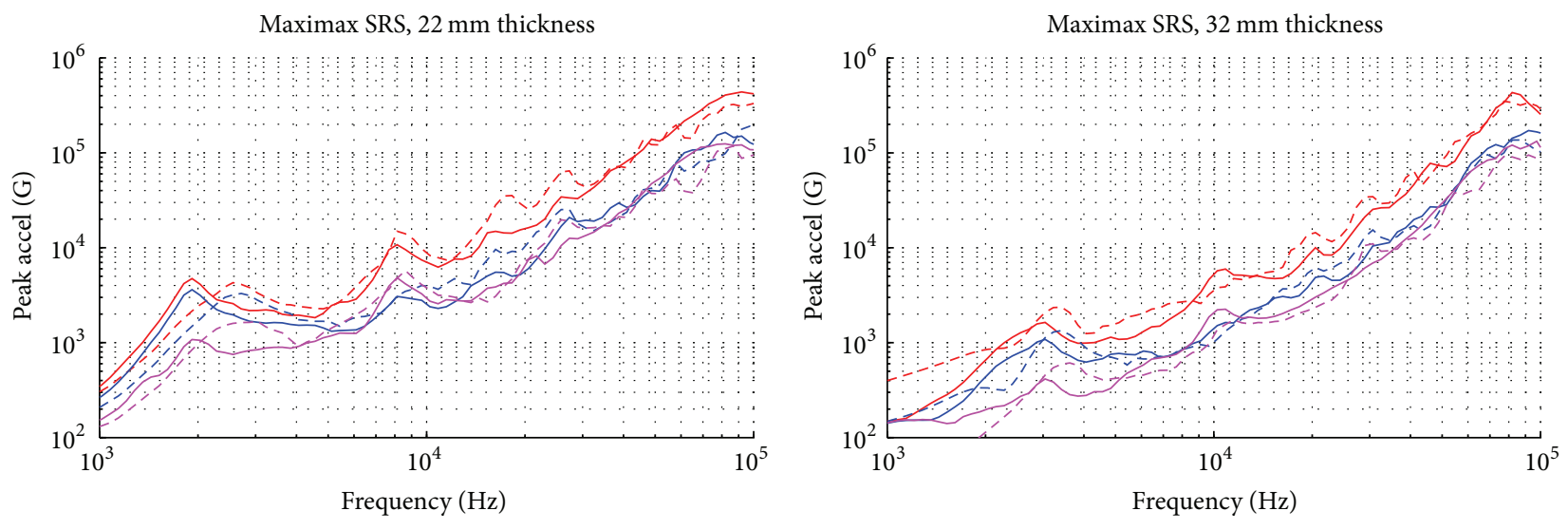

_ $11 \mathrm{~mm}$ point, exp. averaged

- - $11 \mathrm{~mm}$ point, numerical

— $50 \mathrm{~mm}$ point, exp. averaged

- - $50 \mathrm{~mm}$ point, numerical

— $90 \mathrm{~mm}$ point, exp. averaged

- - - $90 \mathrm{~mm}$ point, numerical

(a)

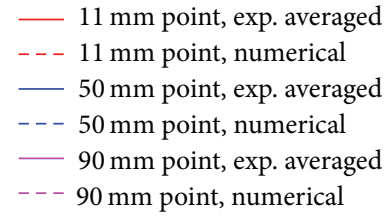

(b)

FIGURE 13: Comparison of maximax SRS between the numerical and averaged experimental results: (a) at a 22 mm thickness circular plate and (b) at a $22 \mathrm{~mm}$ thickness circular plate.

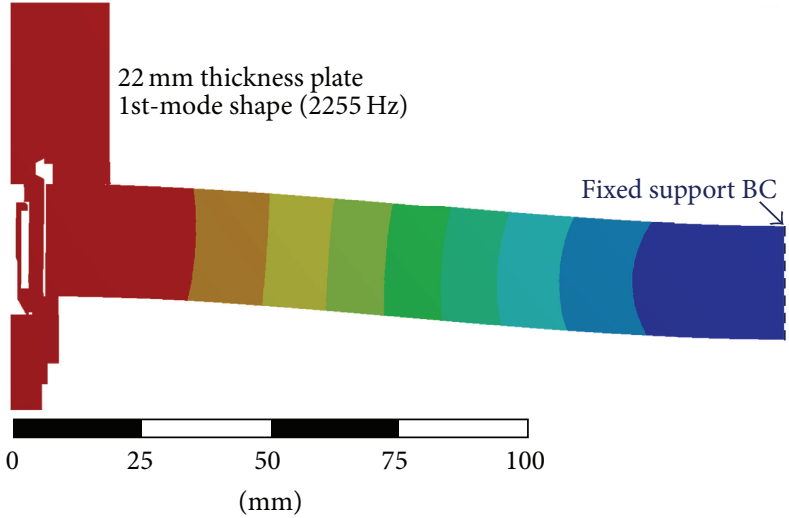

(a)

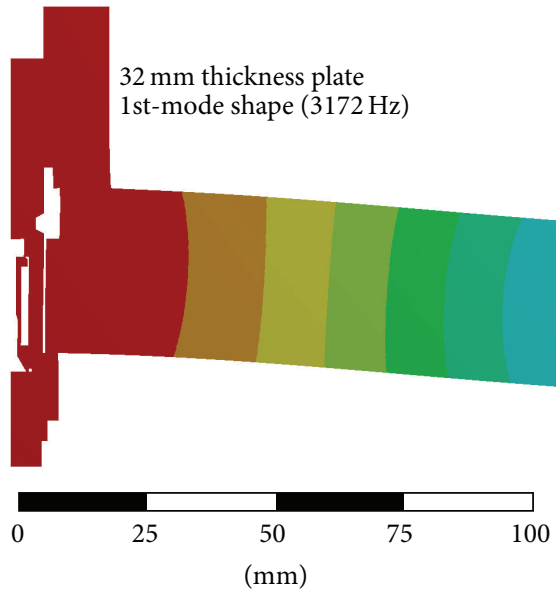

(c)

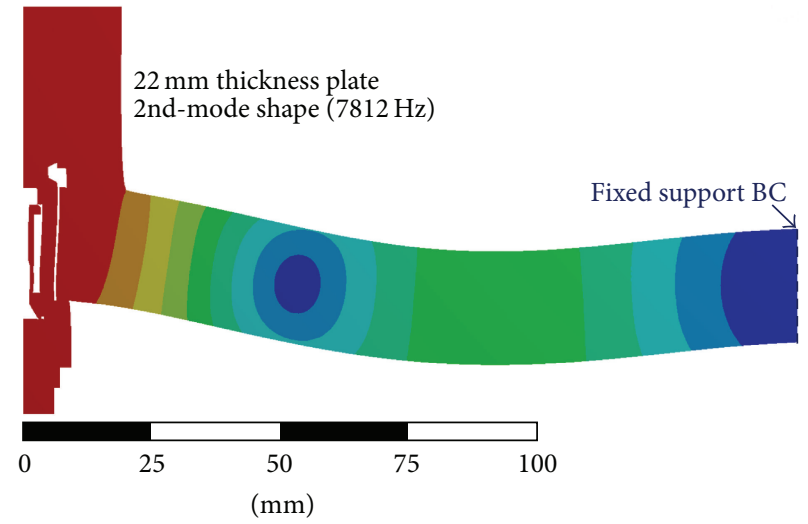

(b)

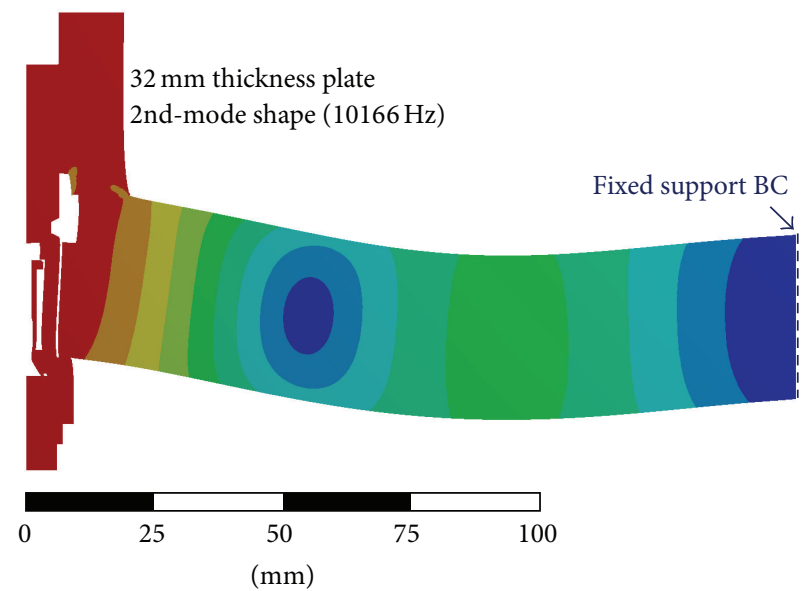

(d)

FIGURE 14: 2D axisymmetric modal analysis results: (a) 1st-mode shape of a bolt with a $22 \mathrm{~mm}$ thickness circular plate, (b) 2nd-mode shape of bolt with a $22 \mathrm{~mm}$ thickness circular plate, (c) 1st-mode shape of a bolt with a $32 \mathrm{~mm}$ thickness circular plate, and (d) $2 \mathrm{nd}$-mode shape of a bolt with a $32 \mathrm{~mm}$ thickness circular plate. 

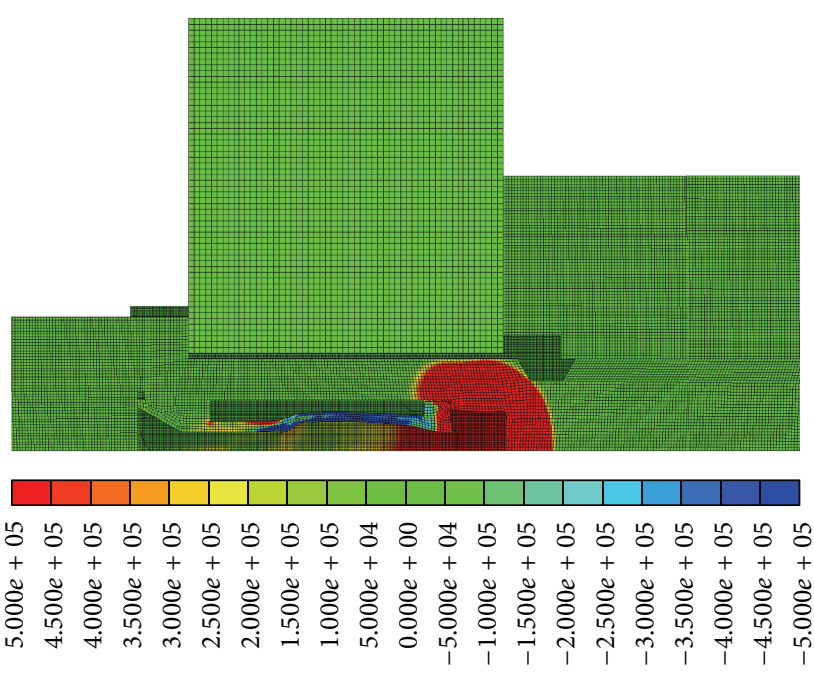

Pressure $(\mathrm{kPa})$

(a)

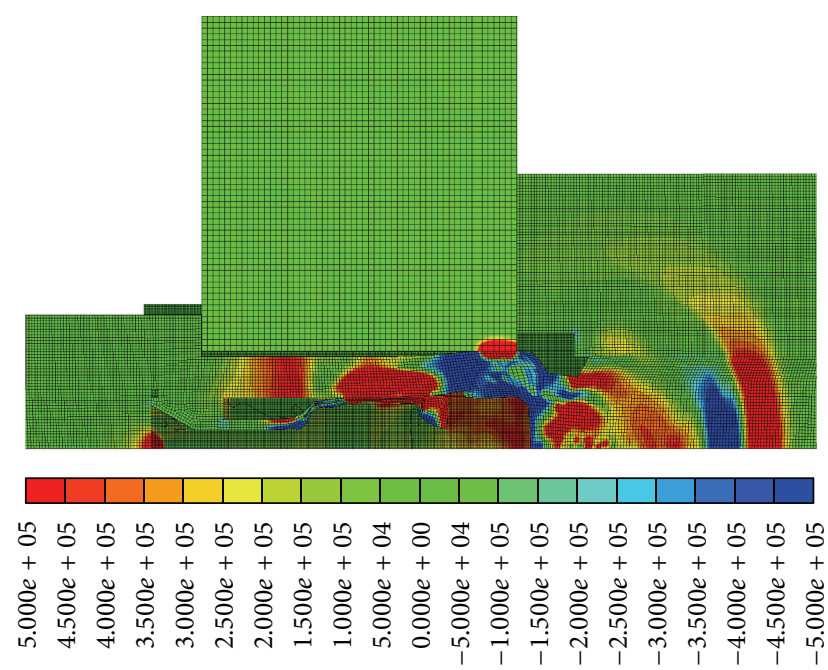

Pressure (kPa)

(b)

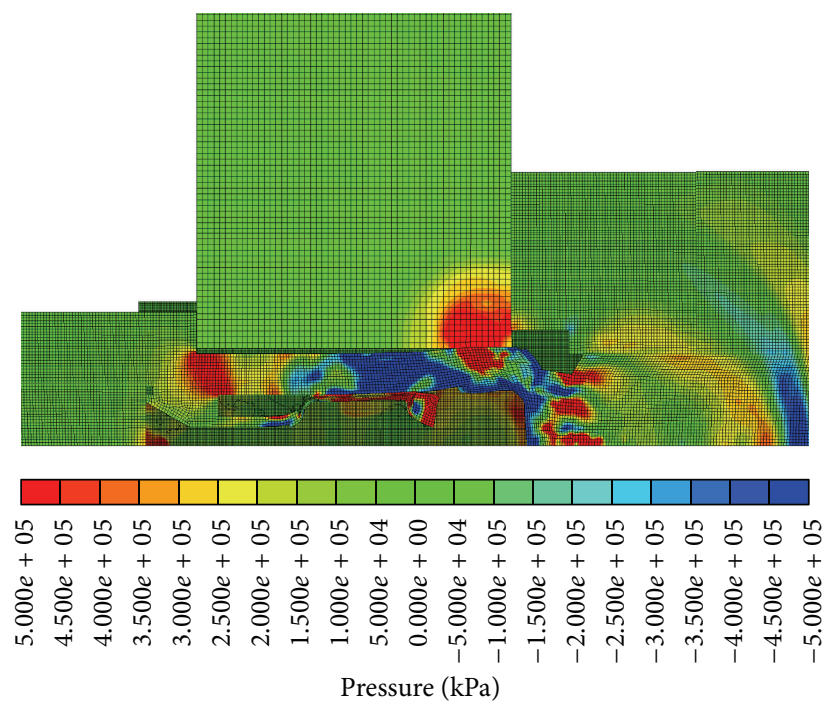

(c)

FIGURE 15: Pressure contours of the ridge-cut explosive bolts with a $22 \mathrm{~mm}$ thickness circular plate: (a) at $2.5 \mu \mathrm{s},(\mathrm{b})$ at $5.1 \mu \mathrm{s}$, and (c) at $6.0 \mu \mathrm{s}$.

are unavailable. Figure 13 shows the comparison between the averaged SRS of the experimental results and the numerical predictions. Apparently, the pyroshock levels are different depending on the measurement positions and the shape of the structures; the numerical results follow that trend.

5.2. Results Discussion. In the maximax SRS, several peaks were observed both in the numerical and in the experimental results. Those peaks were due to the vibration modes of the mounting structures. To obtain the vibration modes of the structures, 2D axisymmetric modal analysis of the structures (bolt, sleeve, fixture, and circular plates) was performed using commercial FEM codes (ANSYS). Only the first two modes for each structure are shown in Figure 14. In the maximax SRS of the $22 \mathrm{~mm}$ thickness circular plate (Figure 13(a)), the frequencies of the first peaks around $2 \mathrm{kHz}$ show some difference between the experiments and analysis. The reason is that the analysis end time is only $1 \mathrm{~ms}$, which is too short to precisely estimate the first mode with a $2 \mathrm{kHz}$ natural frequency. On the other hand, the frequencies of the second peaks are quite well matched. The natural frequency of the second mode is around $8 \mathrm{kHz}$. Here, the second peaks of the experiment and analysis results are not clearly visible at the $50 \mathrm{~mm}$ point, because the $50 \mathrm{~mm}$ point is around the nodal line of the second mode as shown in Figure 14(b). The same explanation applies to the $33 \mathrm{~mm}$ thickness circular plate with the increased natural frequencies.

The numerical analysis of the ridge-cut explosive bolts also helps to understand pyroshock generation and propagation phenomena. First, the shock waves generated by the detonation of the high explosives propagate to the bolt body as shown in Figure 15(a). Most of the shock waves on the bolt 
body originate from RDX due to the detonation direction. Due to the expansion of the bolt body, the bolt body and the circular plate collide around $5 \mu$ s (Figure 15(b)). The shock waves on the circular plate are mainly generated at the collision points and propagated through the collision points as shown in Figure 15(c). Therefore, if the distance between the bolt body and the circular plate is increased to prevent collision, the pyroshock measured on the circular plates significantly decreases. However, the separated bolt body would fly away rather than be stuck to the circular plate. The flying bolt body may hit and damage LDVs; this modification cannot be used.

In a similar manner, the pyroshock generation source and the propagation routes can be identified for the real structures. Using the analysis results, the pyroshock on the structures can be attenuated. However, the reduction of the pyroshock generation and the isolation of the pyroshock propagation routes might degrade the separation reliability of pyrotechnic devices and the structural rigidity of the structures and the bolts.

\section{Conclusion}

This study proposes a numerical method to predict the pyroshock of the ridge-cut explosive bolts. The pyroshocks of the ridge-cut explosive bolts with two types of the surrounding structures were measured at three points using LDVs. Utilizing the established analysis scheme, the pyroshocks at the same points are predicted. Experimental and numerical results are compared in terms of acceleration and maximax SRS; they show good agreement to verify numerical method. The results of this study also provide useful information about how the pyroshocks are generated and propagated to surrounding structures; they can be used to attenuate the pyroshock without expensive explosive experiments.

\section{Competing Interests}

The authors declare that they have no competing interests.

\section{Acknowledgments}

This study was supported by a research program "HighPerformance PMD Technology for Guided Missile" of the Defense Acquisition Program Administration (DAPA) and the Agency for Defense Development (ADD).

\section{References}

[1] K. O. Brauer, Handbook of Pyrotechnics, Chemical Publishing Co, New York, NY, USA, 1974.

[2] L. J. Bement and M. L. Schimmel, A Manual for Pyrotechnic Design, Development and Qualification, NASA, 1995.

[3] M. G. Ryschkewitsch, Pyroshock Test Criteria, NASA, 2011.

[4] A. G. Piersol, T. L. Paez, and C. M. Harris, Harris' Shock and Vibration Handbook, McGraw-Hill, New York, NY, USA, 6th edition, 2010.

[5] DOD, Pyroshock, MIL-STD-810G Method 517.1, Department of Defense, New York, NY, USA, 2008.
[6] IEST, Pyroshock Testing Techniques, Institute of Environmental Sciences and Technology, 2009.

[7] V. I. Bateman, H. Himelblau, and R. Merritt, "Validation of Pyroshock Data," Sound \& Vibration Magazine, 2012.

[8] P. L. Walter, Accelerometer Limitations for Pyroshock Measurements, Sound \& Vibration Magazine, 2009.

[9] V. I. Bateman, "Pyroshock standards," Sound \& Vibration Magazine, 2011.

[10] C. J. Litz Jr., "Laser doppler vibrometer: application of DOE/Taguchi methodologies to pyroshock response spectra," Shock and Vibration, vol. 4, no. 2, pp. 115-123, 1997.

[11] J.-R. Lee, C. C. Chia, and C.-W. Kong, "Review of pyroshock wave measurement and simulation for space systems," Measurement, vol. 45, no. 4, pp. 631-642, 2012.

[12] S. Y. Chong, J. R. Lee, and C. W. Kong, "Shock response spectra reconstruction of pointwise explosive-induced pyroshock based on signal processing of laser shocks," Shock and Vibration, vol. 2014, Article ID 695836, 14 pages, 2014.

[13] J.-K. Jang and J.-R. Lee, "Nondestructive prediction of point source pyroshock response spectra based on experimental conditioning of laser-induced shocks," Optics and Laser Technology, vol. 61, pp. 24-33, 2014.

[14] J.-R. Lee, J.-K. Jang, M. Choi, and C.-W. Kong, "Visualization and simulation of a linear explosive-induced pyroshock wave using Q-switched laser and phased array transducers in a space launcher composite structure," Optics and Laser Technology, vol. 67, pp. 12-19, 2015.

[15] G. Rabbiolo, R. J. Bernhard, and F. A. Milner, "Definition of a high-frequency threshold for plates and acoustical spaces," Journal of Sound and Vibration, vol. 277, no. 4-5, pp. 647-667, 2004.

[16] M. de Benedetti, G. Garofalo, M. Zumpano, and R. Barboni, "On the damping effect due to bolted junctions in space structures subjected to pyro-shock," Acta Astronautica, vol. 60, no. 12, pp. 947-956, 2007.

[17] D. Lee, J. Han, H. Jang, S. Woo, and K. Kim, "Shock response prediction of a low altitude earth observation satellite during launch vehicle separation," International Journal of Aeronautical and Space Sciences, vol. 11, no. 1, pp. 49-57, 2010.

[18] S.-H. Woo and J.-H. Han, "Mid frequency shock response determination by using energy flow method and time domain correction," Shock and Vibration, vol. 20, no. 5, pp. 847-861, 2013.

[19] J. A. Zukas, Introduction to Hydrocodes, Elsevier, Amsterdam, The Netherlands, 2004.

[20] S. K. Roy, M. Trabia, B. O’Toole et al., "Study of hypervelocity projectile impact on thick metal plates," Shock and Vibration, vol. 2016, Article ID 4313480, 11 pages, 2016.

[21] J. Bayandor, R. S. Thomson, M. L. Scott, M. Q. Nguyen, and D. J. Elder, "Investigation of impact and damage tolerance in advanced aerospace composite structures," International Journal of Crashworthiness, vol. 8, no. 3, pp. 297-306, 2003.

[22] N. Tsartsaris, M. Meo, F. Dolce, U. Polimeno, M. Guida, and F. Marulo, "Low-velocity impact behavior of fiber metal laminates," Journal of Composite Materials, vol. 45, no. 7, pp. 803-814, 2011.

[23] F. Abdi, K. Bowcutt, C. Godines, and J. Bayandor, "Collision provoked failure sequencing in space reentry vehicles," Computers and Structures, vol. 89, no. 11-12, pp. 930-939, 2011.

[24] S. V. Perino, J. Bayandor, J. A. Samareh, and S. C. Armand, "Contemporary impact analysis methodology for planetary 
sample return missions," Journal of Spacecraft and Rockets, vol. 52, no. 4, pp. 1217-1227, 2015.

[25] A. J. Siddens, J. Bayandor, and F. Abdi, "Soft impact damage prognosis of F-16 canopy using progressive failure dynamic analysis," Journal of Aircraft, vol. 51, no. 6, pp. 1959-1965, 2014.

[26] J. Lee, J.-H. Han, Y. Lee, and H. Lee, "Separation characteristics study of ridge-cut explosive bolts," Aerospace Science and Technology, vol. 39, pp. 153-168, 2014.

[27] J. Lee, J.-H. Han, Y. Lee, and H. Lee, "A parametric study of ridge-cut explosive bolts using hydrocodes," International Journal of Aeronautical and Space Sciences, vol. 16, no. 1, pp. 5063, 2015.

[28] D. L. Feng, M. B. Liu, H. Q. Li, and G. R. Liu, "Smoothed particle hydrodynamics modeling of linear shaped charge with jet formation and penetration effects," Computers and Fluids, vol. 86, pp. 77-85, 2013.

[29] G. Hussain, A. Hameed, I. Horsfall, P. Barton, and A. Q. Malik, "Experimental and simulation optimization analysis of the Whipple shields against shaped charge," Acta Mechanica Sinica, vol. 28, no. 3, pp. 877-884, 2012.

[30] S. Lim, "Jet velocity profile of linear shaped charges based on an arced liner collapse," Journal of Energetic Materials, vol. 31, no. 4, pp. 239-250, 2013.

[31] M. Choi, J.-R. Lee, and C.-W. Kong, "Development of a numerical model for an expanding tube with linear explosive using AUTODYN," Shock and Vibration, vol. 2014, Article ID 436156, 10 pages, 2014.

[32] E. F. Poncelet, Theory of Ridge-Cut, Stanford Research Institute, Stanford, Calif, USA, 1954.

[33] T. Irvine, An Introduction to the Shock Response Spectrum, Revision S, Vibrationdata, 2012.

[34] M. A. Meyers, Dynamic Behavior of Materials, John Wiley \& Sons, New York, NY, USA, 1994.

[35] P. W. Cooper, Explosives Engineering, VCH, New York, NY, USA, 1996.

[36] G. R. Johnson and W. H. Cook, "A constitutive model and data for metals subjected to large strains, high strain rates and high temperatures," in Proceedings of the 7th International Symposium on Ballistics, pp. 541-547, The Hague, Netherlands, 1983.

[37] E. L. Lee, H. C. Hornig, and J. W. Kury, Adiabatic Expansion of High Explosive Detonation Products, Lawrence Radiation Laboratory, 1968. 


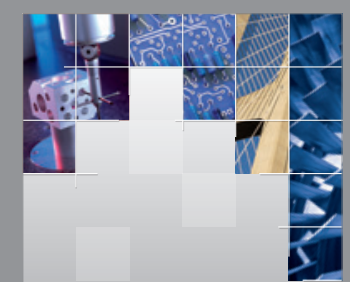

\section{Enfincering}
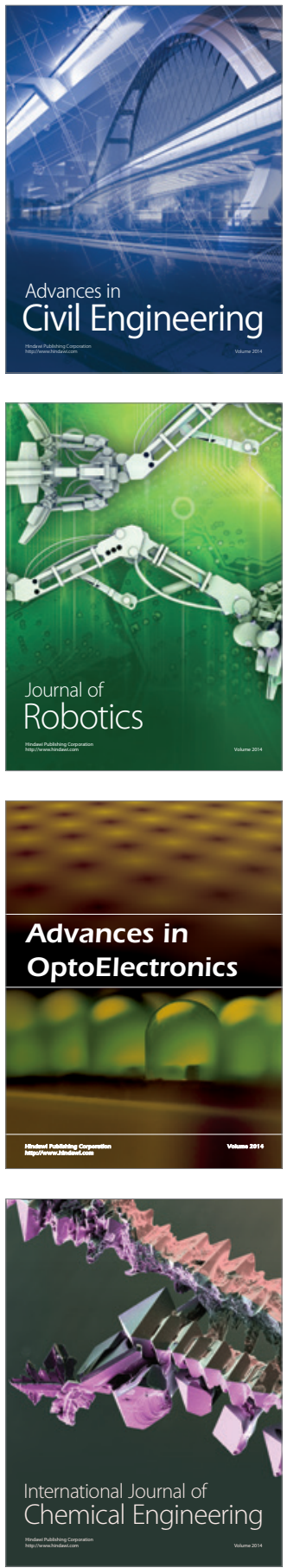

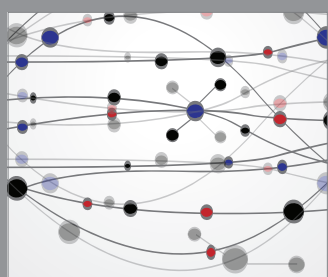

The Scientific World Journal

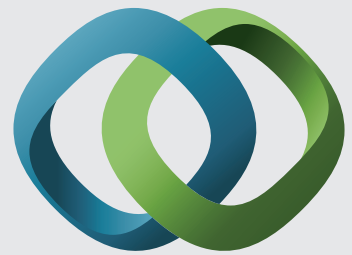

\section{Hindawi}

Submit your manuscripts at

http://www.hindawi.com
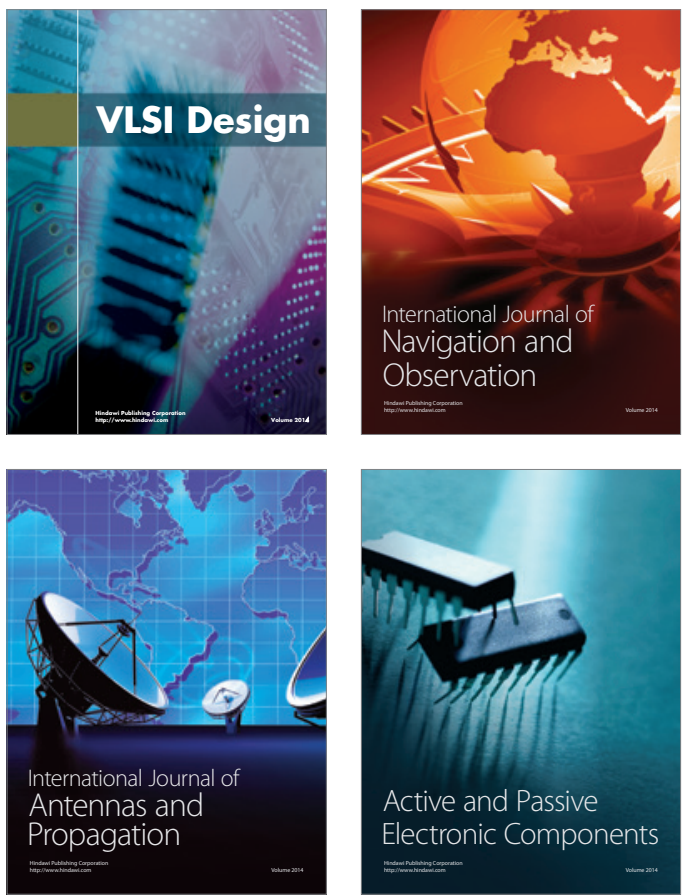
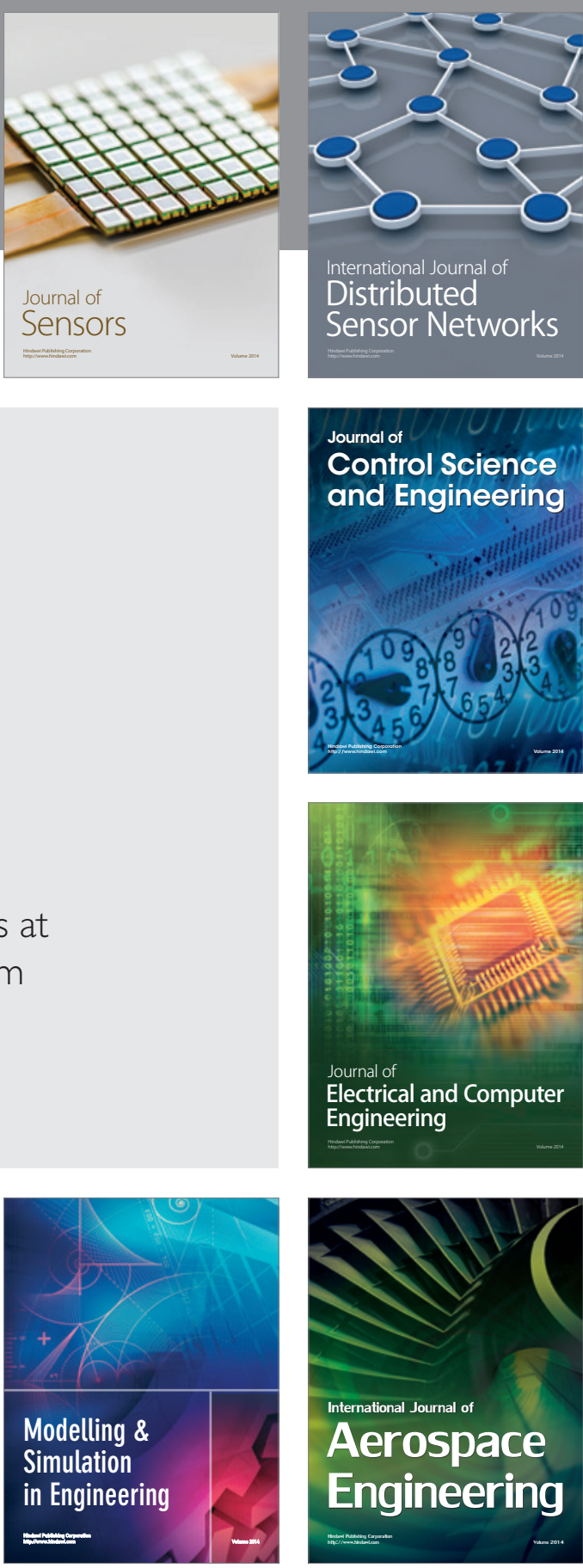

International Journal of

Distributed

Sensor Networks

Journal of

Control Science

and Engineering
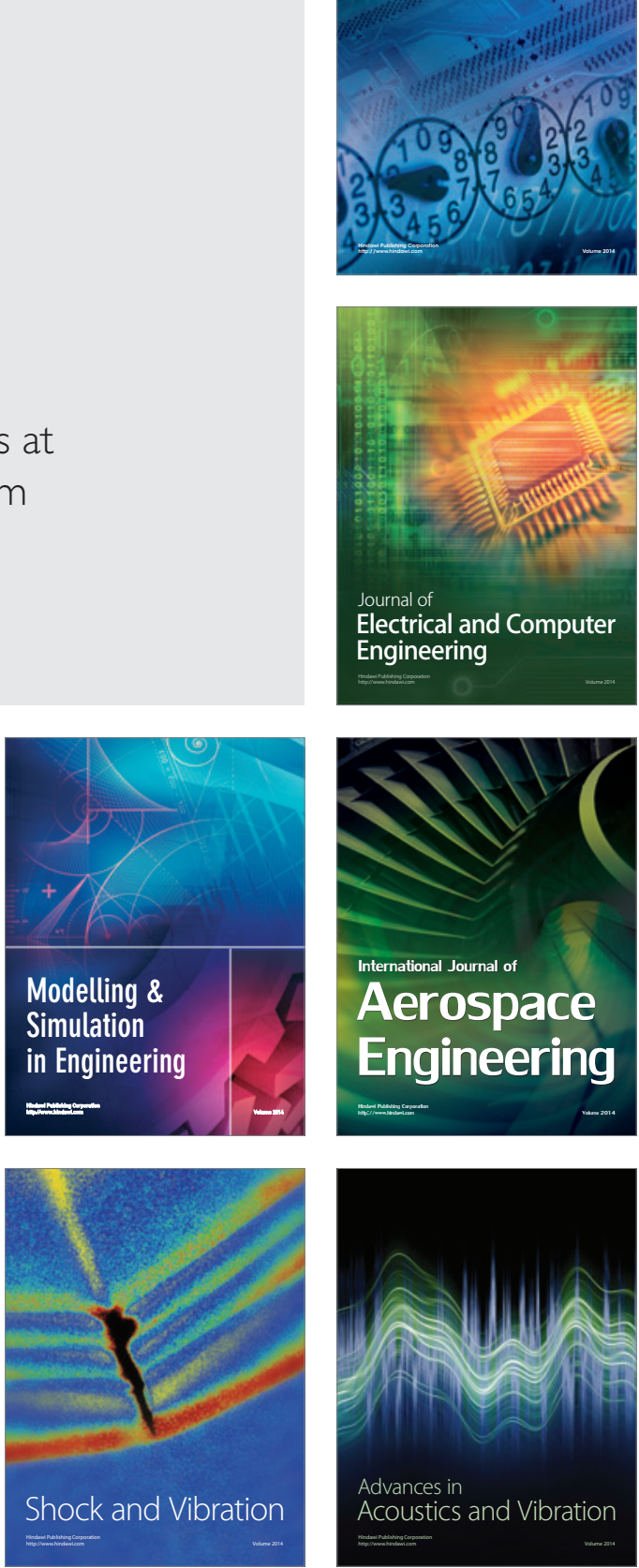